\title{
Blocking follistatin-like 1 attenuates bleomycin-induced pulmonary fibrosis in mice
}

\author{
Yingying Dong, ${ }^{1,2 *}$ Yan Geng, ${ }^{1,3 *}$ Lian Li, ${ }^{1,4 *}$ Xiaohe Li, ${ }^{1}$ Xiaohua Yan, ${ }^{5}$ \\ Yinshan Fang, ${ }^{1}$ Xinxin Li, ${ }^{1}$ Siyuan Dong, ${ }^{1}$ Xue Liu, ${ }^{1}$ Xue Li, ${ }^{1}$ \\ Xiuhong Yang, ${ }^{1}$ Xiaohong Zheng, ${ }^{1}$ Ting Xie, ${ }^{6}$ Jiurong Liang, ${ }^{6}$ \\ Huaping Dai, ${ }^{7}$ Xinqi Liu, ${ }^{1}$ Zhinan Yin, ${ }^{1}$ Paul W. Noble, ${ }^{6}$ Dianhua Jiang, ${ }^{6}$ \\ and Wen Ning ${ }^{1}$
}

\author{
'State Key Laboratory of Medicinal Chemical Biology, College of Life Sciences, Nankai University, Tianjin 300071, China \\ ${ }^{2}$ Cam-Su Genomic Resource Center, Soochow University, Suzhou 215123, China \\ ${ }^{3}$ School of Pharmaceutical Science, Jiangnan University, Wuxi 214122, China \\ ${ }^{4}$ Respiratory Department, Tianjin Medical University General Hospital, Tianjin 300052, China \\ ${ }^{5}$ State Key Laboratory of Biomembrane and Membrane Biotechnology, School of Life Sciences, Tsinghua University, \\ Beijing 100084, China \\ ${ }^{6}$ Department of Medicine, Cedars-Sinai Medical Center, Los Angeles, CA 90048 \\ ${ }^{7}$ Beijing Chao-Yang Hospital, Capital Medical University, Beijing 100020, China
}

\begin{abstract}
Progressive tissue fibrosis is a cause of major morbidity and mortality. Pulmonary fibrosis is an epithelial-mesenchymal disorder in which TGF- $\beta 1$ plays a central role in pathogenesis. Here we show that follistatin-like 1 (FSTL1) differentially regulates TGF- $\beta$ and bone morphogenetic protein signaling, leading to epithelial injury and fibroblast activation. Haplodeletion of Fstl1 in mice or blockage of FSTL1 with a neutralizing antibody in mice reduced bleomycin-induced fibrosis in vivo. Fstl1 is induced in response to lung injury and promotes the accumulation of myofibroblasts and subsequent fibrosis. These data suggest that Fstl1 may serve as a novel therapeutic target for treatment of progressive lung fibrosis.
\end{abstract}

\author{
CORRESPONDENCE \\ Wen Ning: \\ ningwen108@nankai.edu.cn \\ $\mathrm{OR}$ \\ Dianhua Jiang: \\ dianhua.jiang@cshs.org \\ Abbreviations used: AEC, \\ alveolar epithelial cell; BAL, \\ bronchoalveolar lavage; BALF, \\ BAL fluid; BMP, bone mor- \\ phogenetic protein; ECM, \\ extracellular matrix; EMT, \\ epithelial-mesenchymal transi- \\ tion; Fstl1, follistatin-like 1; \\ IPF, idiopathic pulmonary \\ fibrosis; NRVM, neonatal rat \\ ventricular myocyte; $\mathrm{PE}$, \\ phenylephrine; qRT-PCR, \\ quantitative RT-PCR; SPR, \\ surface plasmon resonance.
}

Progressive tissue fibrosis is an increasing cause of morbidity and mortality worldwide with limited therapeutic options. Idiopathic pulmonary fibrosis (IPF), a particularly severe form of lung fibrosis, is a chronic, progressive, and often fatal interstitial lung disease of unknown etiology with a mean survival of 2-3 yr from diagnosis (ATS/ERS, 2000; Olson et al., 2007). The hallmark of IPF is the unremitting extracellular matrix (ECM) deposition with minimal associated inflammation (Noble and Homer, 2004; Wilson and Wynn, 2009). Although evidence suggests that lung fibrosis is an epithelial-mesenchymal disorder (Selman and Pardo, 2002; Chapman, 2011), the mechanisms by which injured epithelium activates fibroblasts/myofibroblasts are unclear. Epithelial apoptosis pathways are activated in the lungs of patients with acute lung injury, in part by activation of signaling pathways such as Fas ligand-Fas and TGF- $\beta$ (Hagimoto et al., 2002). In addition, the injured alveolar epithelial cells (AECs) may also be abnormally activated with phenotypic changes (King et al.,

*Y. Dong, Y. Geng, and L. Li contributed equally to this paper.
2011; Kage and Borok, 2012; Yang et al., 2013). The signals required for this activation are unknown. A recent study suggests that injured kidney epithelial cells produce an increased number of TGF- $\beta$-containing exosomes to activate fibroblasts (Borges et al., 2013). We hypothesized that injured pulmonary epithelial cells may activate mesenchymal cells by releasing soluble factors to promote a fibrogenic microenvironment.

Both TGF- $\beta$ (Sime et al., 1997; Gauldie et al., 2007) and bone morphogenetic protein (BMP) signaling pathways (Costello et al., 2010) play a role in the initiation and progression of fibrosis. They regulate both epithelial cell injury and fibroblast proliferation and transdifferentiation into myofibroblasts at the injury site (Leask and Abraham, 2004; Selman et al., 2008; Goodwin and Jenkins, 2009). BMP4 antagonists have been implicated in fibrotic disorders of multiple organs including lung (Dolan et al., 2003; Patella

0 2015 Dong et al. This article is distributed under the terms of an AttributionNoncommercial-Share Alike-No Mirror Sites license for the first six months after the publication date (see http://www.rupress.org/terms). After six months it is available under a Creative Commons License (Attribution-NoncommercialShare Alike 3.0 Unported license, as described at http://creativecommons.org/ licenses/by-nc-sa/3.0/). 

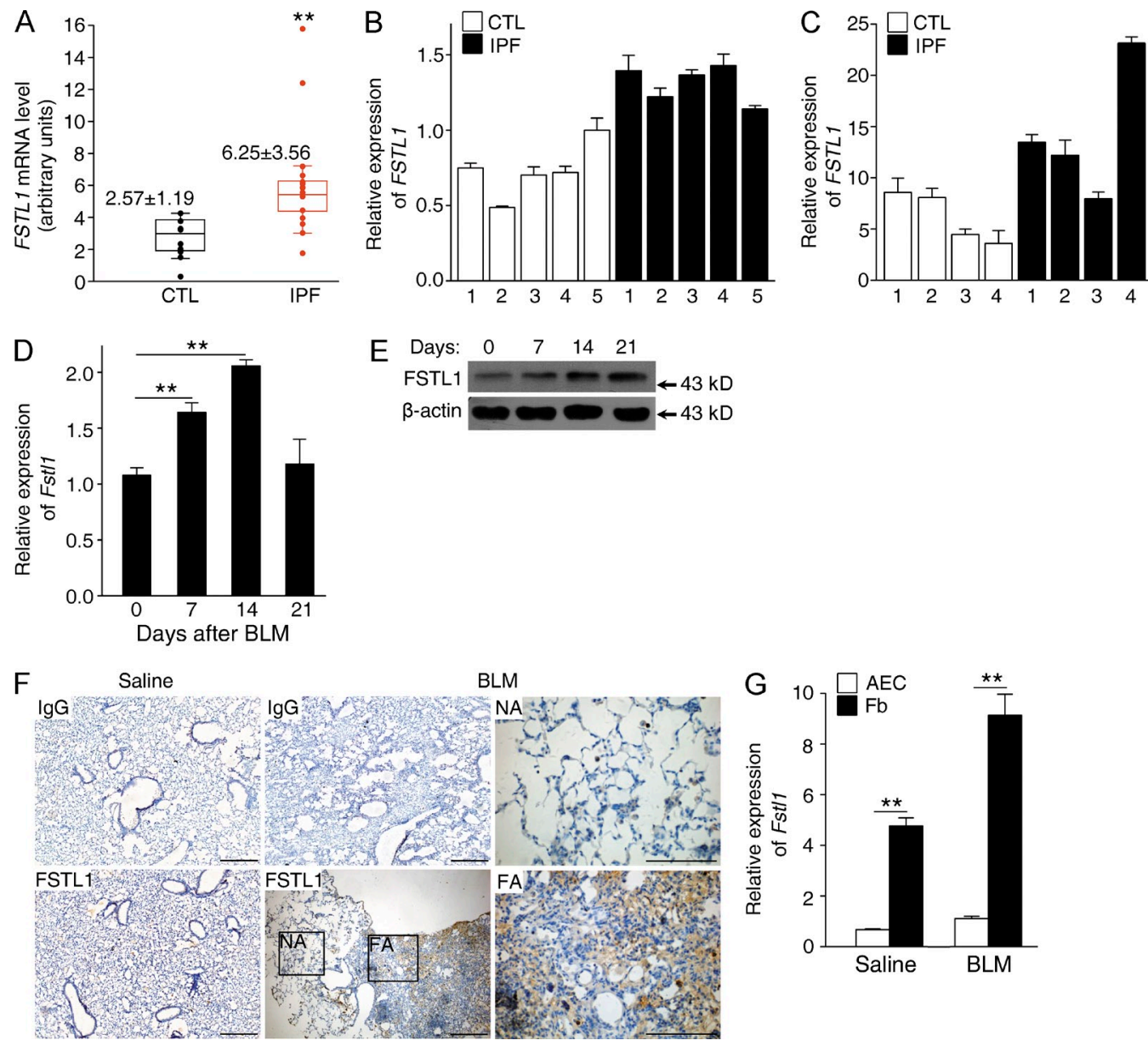

Figure 1. Increased expression of Fstl1 in lungs of IPF patients and bleomycin-injured mice. (A) FSTL1 expression in IPF lung tissues was examined in a published gene-profiling dataset of IPF lungs. Microarray analysis of FSTL1 mRNA in lung samples of IPF patients $(n=15)$ compared with control subjects ( $C T L ; n=11)$. Boxes indicate the middle two quartile values, with the median values shown. Error bars represent $1.5 \times$ the interquartile range. ${ }^{*}, \mathrm{P}=0.003$. (B and C) qRT-PCR analysis of FSTL1 mRNA expression in lung tissues from independent IPF patients $(n=5)$ and control subjects $(n=5 ; \mathrm{B})$ and primary lung fibroblasts derived from other independent IPF patients $(n=4)$ and control subjects $(n=4 ; C)$. GUSB was used as an internal control. (D) qRT-PCR analysis of Fst/1 mRNA expression in lung tissues of C57BL/6J mice at the indicated time points after $2.5 \mathrm{U} / \mathrm{kg}$ bleomycin treatment (BLM; $n=6$ per group). ${ }^{*}, \mathrm{P}<0.01$. (E) Western blot analysis of FSTL1 protein induction in lung tissues of $\mathrm{C} 57 \mathrm{BL} / 6 \mathrm{~J}$ mice at the indicated time points after $2.5 \mathrm{U} / \mathrm{kg}$ bleomycin treatment ( $n=5$ per group). $\beta$-Actin was used as a loading control. (F) Immunohistochemistry of FSTL1 in lung sections of C57BL/6J mice $14 \mathrm{~d}$ after saline or $2.5 \mathrm{U} / \mathrm{kg}$ bleomycin treatment. Representative images of the staining are shown ( $n=3$ per group). IgG staining was used as a control. NA stands for normal area, FA stands for fibrotic area; both are shown at higher magnification. Bars, $100 \mu \mathrm{m}$. (G) qRT-PCR analysis of Fst/1 mRNA expression in primary AECs and fibroblasts (Fb) newly isolated from lung tissues of $\mathrm{C} 57 \mathrm{BL} / 6 \mathrm{~J}$ mice $14 \mathrm{~d}$ after saline or $2.5 \mathrm{U} / \mathrm{kg}$ bleomycin treatment ( $n=5$ per group). ${ }^{* *}, P<0.01$. (B-G) The experiments were performed three times. (B-D and $G$ ) Error bars indicate mean \pm SEM.

et al., 2006; Costello et al., 2010). The precise mechanisms of TGF- $\beta$ superfamily members in regulating lung fibrogenesis in specific cell types are largely unclear.

Follistatin-like 1 (FSTL1), initially identified as a TGF$\beta$-inducible gene (Shibanuma et al., 1993), encodes a small secreted glycoprotein belonging to a group of matricellular proteins. We recently reported that Fstl1 acts as a BMP4 antagonist to play a key role in lung development (Geng et al., 2011). The role of FSTL1 in lung fibrosis has not been investigated. In this study, we have interrogated the role of FSTL1regulated TGF- $\beta / \mathrm{BMP}$ signaling in different cell types during lung injury and fibrosis. We report that FSTL1 mediates epithelial-mesenchymal communication at the cellular level.
We found that FSTL1 modulated TGF- $\beta$ but not BMP signaling, leading to fibroblast activation. We provide evidence that targeting FSTL1 may offer a novel therapeutic approach for patients with progressive tissue fibrosis.

\section{RESULTS}

Aberrant expression of FSTL1 in lungs of IPF patients and bleomycin-injured mice

We first determined whether FSTL1 expression is aberrant in progressive lung fibrotic diseases. We analyzed FSTL1 expression in a gene-profiling dataset of IPF lungs published (Pardo et al., 2005) and identified a 2.4-fold increase in FSTL1 mRNA expression in IPF lung tissues compared with control subjects 
(Fig. 1 A). The increased FSTL1 mRNA expression was then confirmed using quantitative RT-PCR (qRT-PCR) analysis in lung tissue samples from an independent cohort of IPF patients $(1.7$-fold, $\mathrm{P}<0.05$; Fig. $1 \mathrm{~B})$ and in primary lung fibroblasts from another cohort of IPF patients (2.3-fold; Fig. 1 C). In addition, we examined the expression of Fstl1 using the bleomycin model of lung injury and fibrosis (Moeller et al., 2008). As shown in Fig. 1 (D and E), bleomycin-induced injury stimulated Fstl1 mRNA and protein expressions. We also observed considerably increased FSTL1 immunohistochemical staining in active fibrotic areas (Fig. 1 F). Furthermore, we found that the increased FSTL1 production was mainly from mesenchymal cells, as indicated by the significantly higher mRNA level of Fstl1 in newly isolated lung fibroblasts than that of epithelial cells (Fig. $1 \mathrm{G}$ ). These data suggest that Fstl1 is a fibrosis-related gene and may be critical for the pathogenesis of pulmonary fibrosis.

\section{Fstl1 ${ }^{+/-}$mice have an attenuated fibrotic phenotype after lung injury}

To investigate the biological significance of the inducible expression of Fstl1 during fibrogenesis, we examined the fibrotic response to bleomycin-induced lung injury in Fstl1-deficient mice. Because homozygous Fstl1 ${ }^{-/-}$mice die of respiratory failure shortly after birth (Geng et al., 2011), heterozygous Fstl1 ${ }^{+/-}$mice were used to study the fibrotic response to bleomycin injury. Fstl1 $1^{+/-}$mice made significant less FSTL1 protein in the lung tissue ( $\sim 59 \%$ decrease), and bleomycininduced increase of FSTL1 protein was dramatically reduced in Fstl1 $1^{+/-}$lungs ( $~ 57 \%$ decrease; Fig. 2 A). Fstl1 $1^{+/-}$mice were significantly less susceptible to bleomycin-induced lung injury and showed an increase in survival relative to WT littermates (Fig. 2 B). Importantly, Fstl1 $1^{+/-}$mice exhibited reduced lung fibrosis. Collagen accumulation was significantly reduced in lung tissue of Fstl1 $1^{+/-}$mice, as determined by hydroxyproline content (Fig. 2 C) and Masson's trichrome staining (Fig. 2 D). Quantification of fibrotic lung sections by a blinded pathologist illustrated the attenuated fibrosis in Fstl1 ${ }^{+/-}$mice (Fig. 2 E). The attenuated fibrosis in Fstl1 ${ }^{+/-}$ mice was further supported by decreased mRNA and protein levels for type I collagen and fibronectin (Fig. 2, F-I). These in vivo data indicate that Fstl1 is induced in response to lung injury and causally involved in driving pulmonary fibrogenesis as a profibrotic factor.

\section{Fst $11^{+/-}$mice exhibit normal inflammatory response after bleomycin treatment}

Persistent inflammation often drives fibrotic progression in the bleomycin injury model, although the contribution of inflammation to fibrogenesis is controversial (Wynn, 2008). Previous studies have implicated a role of FSTL1 in inflammatory response in rheumatoid arthritis (Clutter et al., 2009) and in heart allograft rejection (Le Luduec et al., 2008). We analyzed the inflammatory response of $\mathrm{Fstl}^{+/-}$mice $7 \mathrm{~d}$ after bleomycin treatment. Notably, compared with WT mice, the increase of inflammatory cells was comparable in Fstl1 $1^{+/-}$ mice (Fig. 3 A). Consistently, FACS analysis showed no major differences in immune cell subset infiltration, such as $\mathrm{CD}^{+}, \mathrm{CD}^{+}, \mathrm{NKT}, \mathrm{NK}$, and B cells, as well as alveolar and interstitial macrophages and neutrophils, in lung tissues between the mouse strains (Fig. 3 B). A Th1/Th2 imbalance has been suggested to play a role in fibrogenesis (Wynn, 2008). We measured cytokines IFN- $\gamma$ (Th1), IL-13 (Th2), IL-6, IL-1及, IL-17A, and TNF, whose dysregulation has been reported in lung tissue of IPF patients (Agostini and Gurrieri, 2006; Wynn, 2011) and in animal models (Saito et al., 2008; Wynn, 2008). As shown in Fig. 3 C, similar concentrations of cytokines were measured by ELISA in the bronchoalveolar lavage (BAL) fluid (BALF) and homogenized lung tissue from Fstl1 $^{+/-}$and WT littermates. These data suggest that deletion of Fstl1 attenuates bleomycin-induced lung fibrosis without affecting the inflammatory response in response to lung injury.

\section{Fst/1+/- mice display decreased myofibroblast accumulation after bleomycin treatment}

The accumulation of fibroblasts with an activated phenotype (named as myofibroblasts) in the fibrotic foci characterizes progressive pulmonary fibrosis (Scotton and Chambers, 2007; Phan, 2012). To examine whether the attenuated fibrotic phenotype in Fstl1 ${ }^{+/-}$mice is associated with the changed accumulation of myofibroblasts, we performed immunohistochemistry on lung sections with anti- $\alpha$-SMA antibodies, a marker for newly appearing myofibroblasts. As shown in Fig. 4 A, bleomycin-increased myofibroblast accumulation was apparent in WT mice, but not in Fstl1 ${ }^{+/-}$mice. Consistently, qRT-PCR and immunoblotting analyses of lung tissues showed that bleomycin-induced expression of $\alpha$-SMA in WT mice was significantly decreased in Fstl1 ${ }^{+/-}$mice (Fig. 4, $\mathrm{B}$ and $\mathrm{C}$ ). Meanwhile, we observed that the mRNA level of Fsp-1, a marker for fibroblasts, was lower in Fstl1 ${ }^{+/-}$mice than that in WT (Fig. 4 D). These data suggest that Fstl1 deficiency is protective against fibrogenesis, possibly via limiting the bleomycin-induced accumulation of myofibroblasts.

To further verify this conclusion, we isolated mouse lung fibroblasts from mice $14 \mathrm{~d}$ after bleomycin treatment and quantified the subpopulation of $\alpha$-SMA-expressing myofibroblasts with FACS. A large subpopulation of $\alpha-\mathrm{SMA}^{+}$myofibroblasts was identified in fibroblasts from bleomycin-treated WT mice, whereas the subpopulation of $\alpha-\mathrm{SMA}^{+}$myofibroblasts was much smaller from Fstl1 ${ }^{+/-}$mice (Fig. 4 E). The ratio of myofibroblasts/fibroblasts of $\mathrm{Fstl}^{+/-}$was 37\% less than that of WT (Fig. 4 E). Double immunostaining for $\alpha$-SMA and vimentin (a fibroblast marker) showed a similar result with few costaining myofibroblasts found in fibroblasts from Fstl1 $^{+/-}$mice (Fig. 4, F and G). Western blotting analysis confirmed the limited accumulation of myofibroblasts, as indicated by diminished $\alpha$-SMA, type I collagen, and fibronectin expression in fibroblasts isolated from bleomycin-treated Fstl1 $1^{+/-}$lungs (Fig. $4 \mathrm{H}$ ). Collectively, the attenuated fibrosis in Fstl1 $1^{+/-}$mice is associated with limited myofibroblast accumulation and subsequently less ECM production. 

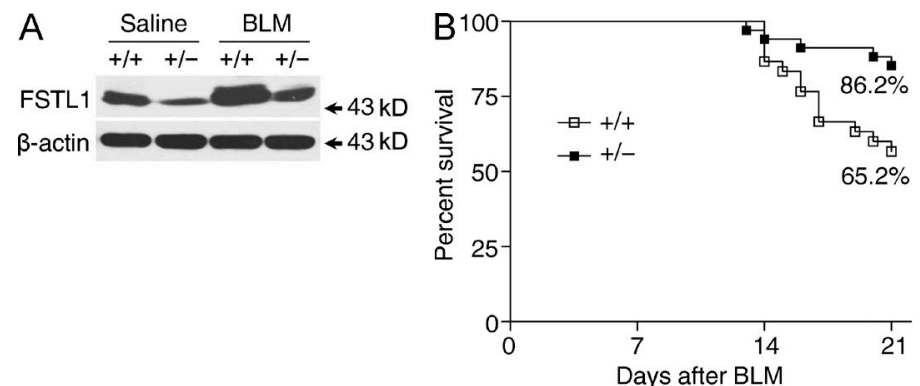

D
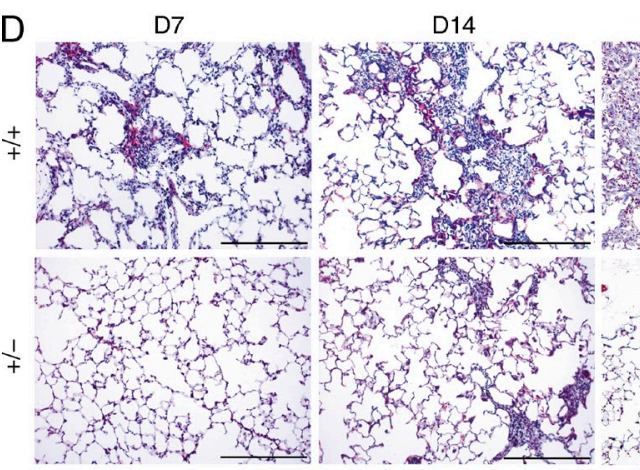

D21

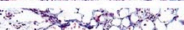
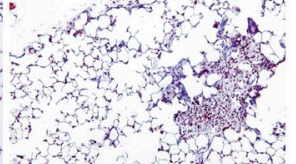
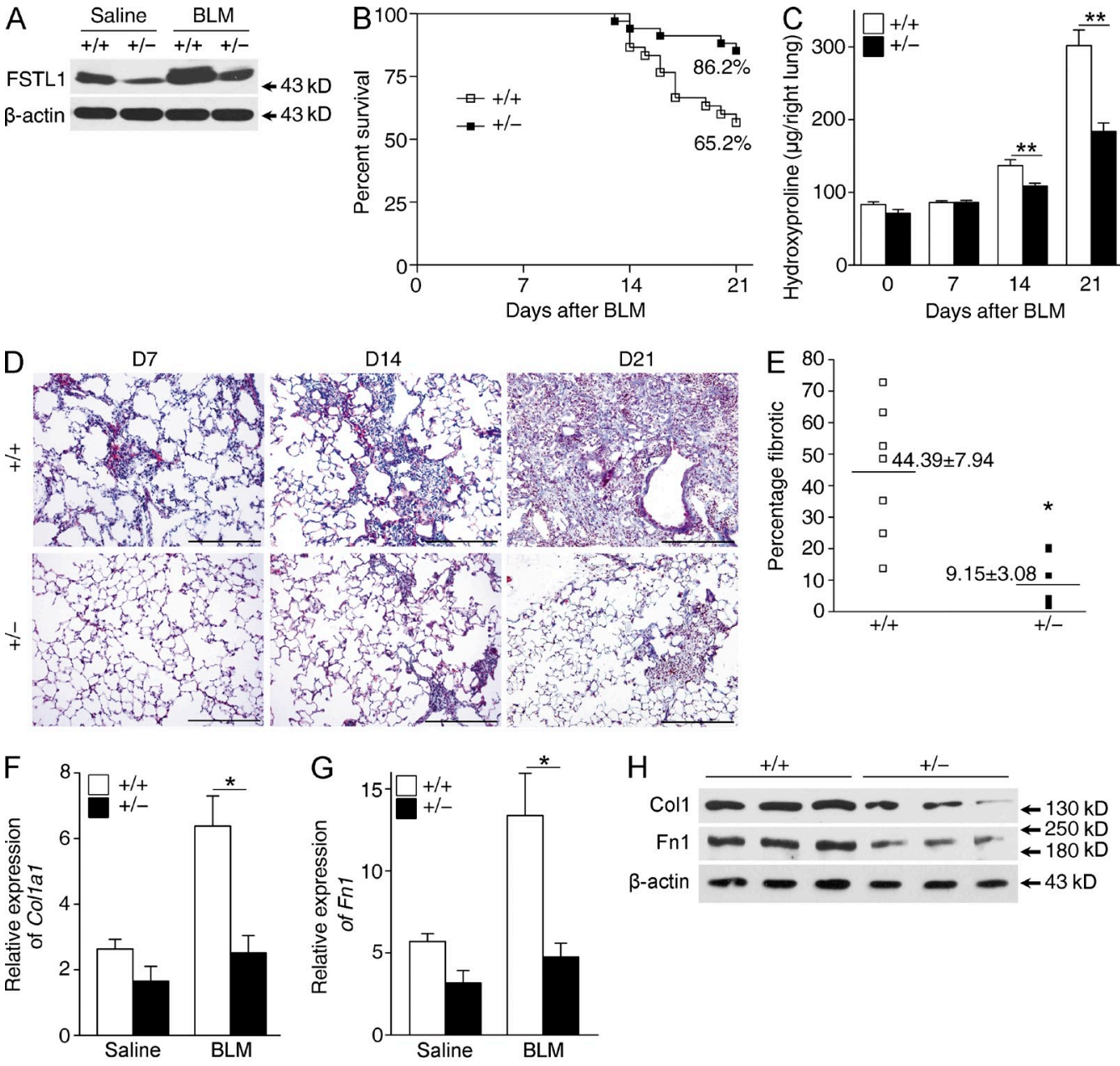

$+1+$

$H$
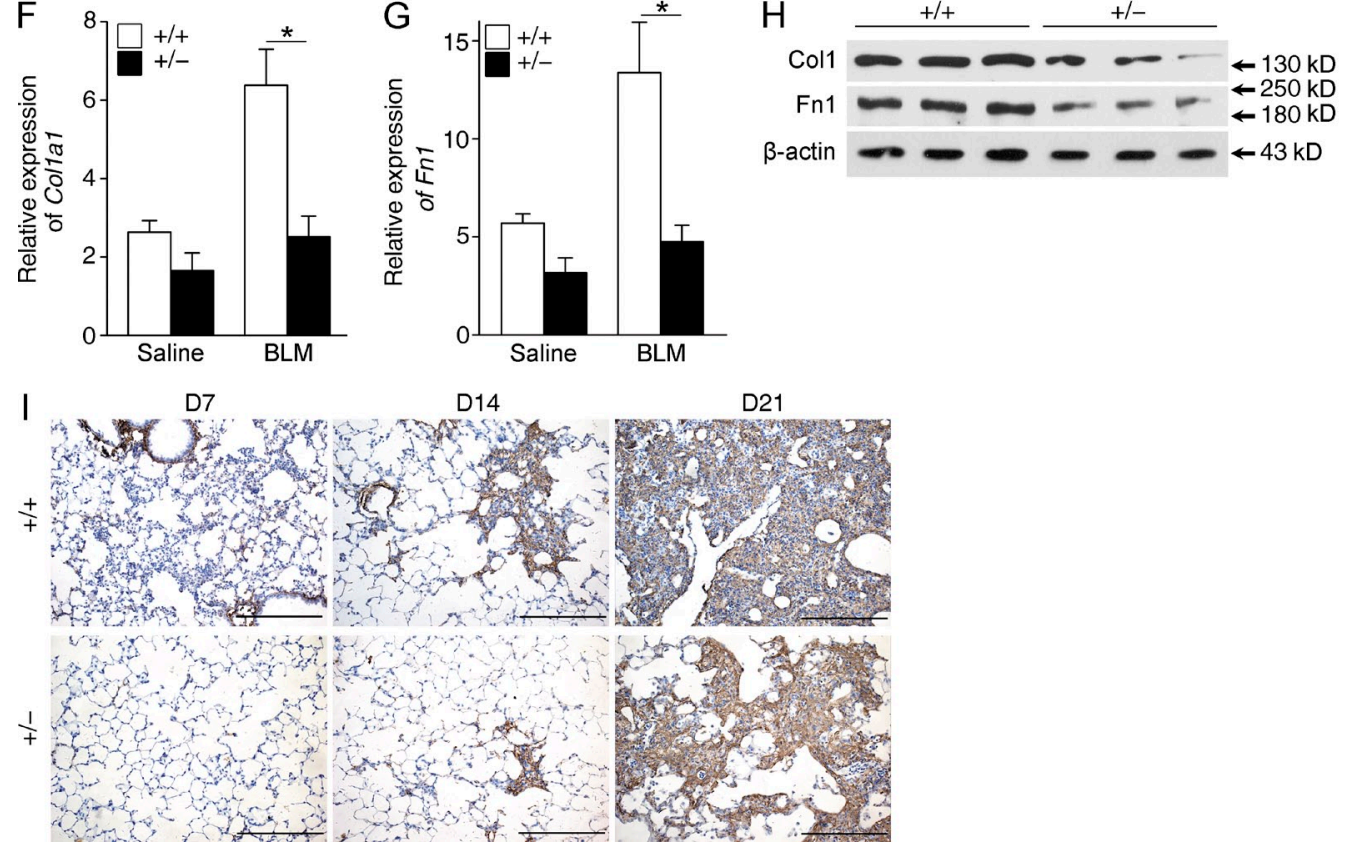

Figure 2. Attenuated pulmonary fibrosis in Fst/1 ${ }^{+/-}$mice. Fst $/ 1^{+/-}$and their WT littermates were subjected to $5 \mathrm{U} / \mathrm{kg}$ bleomycin-induced lung injury, and lungs at the indicated time points were harvested for the following analyses. (A) Western blot analysis of FSTL1 expression in lung tissues $14 \mathrm{~d}$ after saline or bleomycin treatment (BLM; $n=5$ per group). Genotypes are indicated $\left(+/+, W T_{i}+l-\right.$, Fst $\left./ 1^{+-}\right)$. (B) Percentages of surviving mice were plotted over a 21-d period after bleomycin treatment. Log-rank test was used to compare the difference between Fst/1 $1^{+-}$and WT mice $(n=29$ per group): $\mathrm{P}=$ 0.012. (C) Hydroxyproline contents in lung tissues from Fst $/ 1^{+/-}$and WT mice $0,7,14$, and $21 \mathrm{~d}$ after bleomycin treatment were measured $(n=7$ per group: $\left.{ }^{*}, P<0.01\right)$. (D) Masson trichrome staining of collagen on lung sections from Fst/1 ${ }^{+/-}$and WT mice 7, 14, and $21 \mathrm{~d}$ after bleomycin treatment. Representative images of the staining are shown ( $n=7$ per group). (E) Lung fibrotic score analysis of the Masson trichrome staining D21 lung sections. The fibrotic area is presented as a percentage. Horizontal lines indicate the mean. ${ }^{*}, \mathrm{P}=0.02$. $(\mathrm{F}-\mathrm{H}) \mathrm{Fst} / 1^{+/-}$and WT mice were treated with saline or bleomycin treatment for $14 \mathrm{~d}$ ( $n=5$ per group), and lung tissues were harvested for the following analyses. qRT-PCR analysis of Col1a 1 (F) and fibronectin (Fn 1; G) mRNA expressions $\left({ }^{*}, \mathrm{P}<0.05\right)$ and Western blot analysis of type I collagen (Col1) and fibronectin (Fn $\left.1 ; H\right)$. (A and H) $\beta$-Actin was used as a loading control. (I) Immunohistochemical analysis of collagen I in lung sections. Representative images of the staining are shown ( $n=7$ per group). (D and I) Bars, $100 \mu \mathrm{m}$. (A-D and F-I) The experiments were performed three times. ( $C, F$, and $G)$ Error bars indicate mean \pm SEM. 

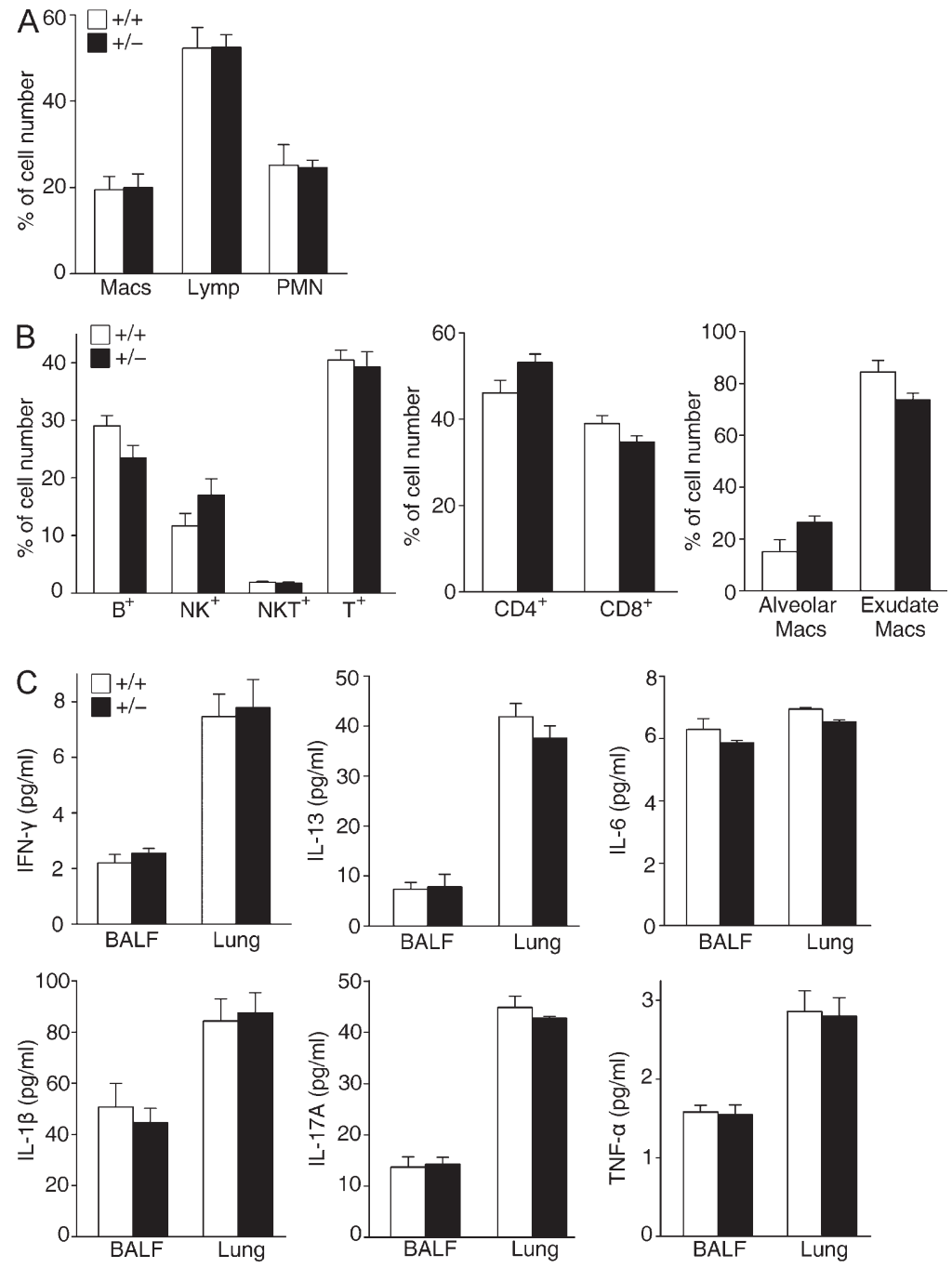

Figure 3. Similar inflammatory response in Fst/1+/mice. Fst $/ 1^{+/-}$and their WT littermates were subjected to $2.5 \mathrm{U} / \mathrm{kg}$ bleomycin-induced lung injury for $7 \mathrm{~d}$. (A) BALF cells were collected from lung tissues, and percentage of differential BALF cell numbers was determined $(n=9$ per group). (B) FACS analysis of inflammatory cells in lung tissues with specific antibodies to CD3, CD8, CD4, B cell marker (B220), and the NK cell marker (NK1.1). Percentages of $\mathrm{CD}^{+}, \mathrm{CD}^{+}, \mathrm{B}^{2} 20^{+}$, and $\mathrm{NK} 1.1^{+}$cells were plotted. FACS analysis of macrophages using specific antibodies to macrophage cell markers (CD11c and Gr-1), alveolar macrophage cell marker (CD11b), and interstitial macrophage cell marker (IA-b; $n=6$ per group) is shown. (C) ELISA analysis of IFN- $\gamma$, IL-13, IL-6, IL-1 $\beta, I L-17 A$, and TNF expressions in BALF and lung tissues ( $n=6$ per group). (A-C) The experiments were performed three times. Error bars indicate mean \pm SEM.

\section{Fstl1 deficiency protects epithelial cells from injury}

Evidence suggests that lung fibrosis is a dysregulated epithelialmesenchymal disorder, in which epithelial injury is an initiating event (Selman and Pardo, 2002). Haplodeletion of Fstl1 showed a significant reduction of lung architectural damage $7 \mathrm{~d}$ after bleomycin injury (Fig. $5 \mathrm{~A}$ ). Injured AECs likely undergo many cellular and molecular changes and may create a profibrotic environment in an effort to activate fibroblasts. Injured AECs may lose epithelial markers and gain mesenchymal markers at the same time (King et al., 2011; Kage and Borok, 2012). We isolated AECs from WT mice $7 \mathrm{~d}$ after bleomycin treatment. We found decreased mRNA expression of epithelial markers, such as Sftpc, E-cadherin (Cdh1), Occludin (Ocln), and ZO-1, and increased mRNA expression of mesenchymal markers, such as $\boldsymbol{\alpha}-S M A$, vimentin (Vim), and Fsp1 (Fig. 5, B and C). FACS analysis (Fig. 5 D) also showed increased numbers of E-Cad ${ }^{+}$Fsp $1^{+}$ AECs in response to bleomycin injury, supporting the notion that injured AECs are activated and may express mesenchymal genes. We performed double immunostaining for
$\alpha$-SMA and pro-SPC on WT lung sections and identified costaining of pro-SPC ${ }^{+} \alpha-\mathrm{SMA}^{+}$AECs on days 7 and 14 after bleomycin treatment (Fig. $5 \mathrm{E}$ ), confirming that epithelial cells with a mesenchymal phenotype serve as a marker of epithelial injury. Notably, Fstl1 haplodeficiency inhibited bleomycin-induced expression of mesenchymal markers and restored the expression of epithelial markers in Fstl1 ${ }^{+/-}$ AECs (Fig. 5, B and C). In addition, the bleomycin-increased numbers of mesenchymal markers expressing AECs were significantly decreased in Fstl1 $1^{+/-}$epithelial cells (Fig. 5, D and E), indicating that Fstl1 deficiency in Fstl1 ${ }^{+/-}$mice is protective against bleomycin-induced epithelial injury.

\section{FSTL1 moderates epithelial-mesenchymal communication}

We next investigated whether diminished epithelial cell activation in Fstl1 $1^{+/-}$mice attenuated myofibroblast activation and fibrosis. We reasoned that injured epithelial cells may influence fibroblast activation through cell-cell contact or release of soluble factors. Using a transwell co-culture assay with primary AECs in the upper chamber and fibroblasts 

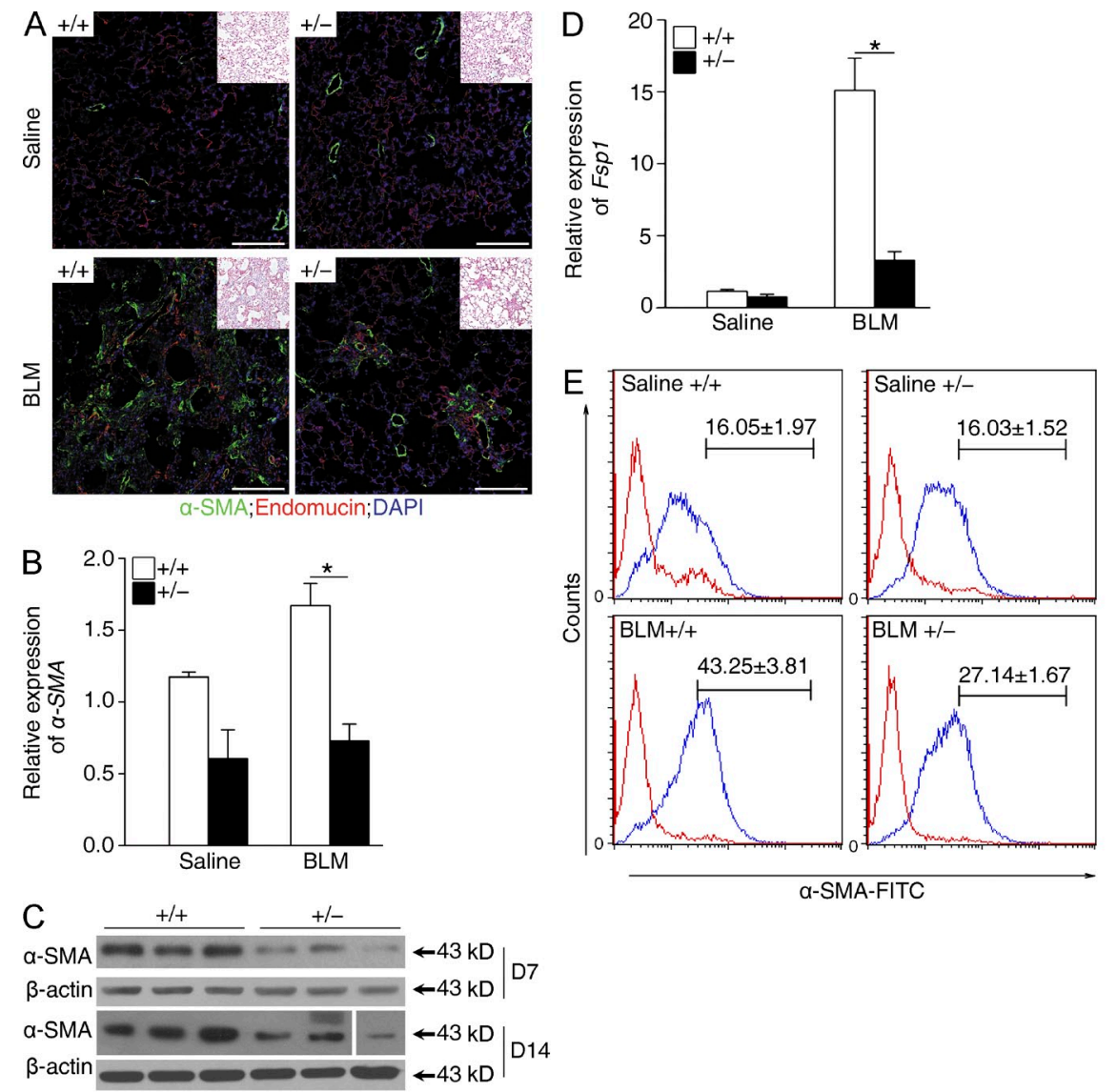
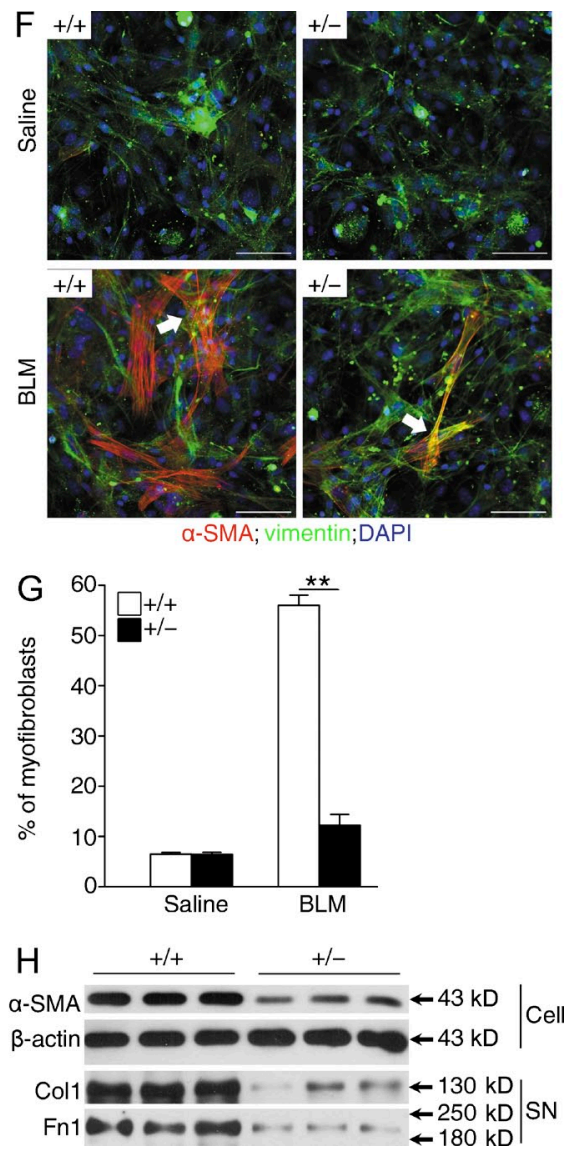

Figure 4. Reduced accumulation of myofibroblasts in Fst/1 $1^{+/-}$mouse lungs. Fst/1 $1^{+-}$and their WT littermates were treated with saline or $2.5 \mathrm{U} / \mathrm{kg}$ bleomycin (BLM) for $14 \mathrm{~d}$. (A) Immunofluorescence analysis of $\alpha$-SMA expression in lung sections (nucleus, DAPI; $n=6$ per group). Representative images of the staining are shown. Note that myofibroblast staining (green) is not co-located with blood vesicles (red). Insets show hematoxylin and eosin staining of the adjacent section. (B) qRT-PCR analysis of $\alpha$-SMA mRNA expression in lung tissues ( $n=6$ per group). ${ }^{*}, \mathrm{P}<0.05$. (C) Western blot analysis of $\alpha$-SMA expression in lung tissues 7 and $14 \mathrm{~d}$ after bleomycin treatment ( $n=5$ per group). The white line indicates intervening lanes have been spliced out. (D) qRT-PCR analysis of Fsp $1 \mathrm{mRNA}$ expression in lung tissues ( $n=6$ per group). ${ }^{*}, \mathrm{P}<0.05$. (E) Newly isolated lung fibroblasts from Fst/1 ${ }^{+/-}$and WT mice $14 \mathrm{~d}$ after saline or bleomycin treatment ( $n=6$ per group) were stained for goat anti-rabbit lgG control (red lines) or $\alpha$-SMA-FITC (blue lines). The proportions of $\alpha$-SMApositive cells (myofibroblasts) were determined. Mean percentages of $\alpha$-SMA+ cells in lung fibroblasts were summarized in the upper region of each panel. The experiments were performed twice. (F) Immunofluorescent staining of myofibroblasts in lung fibroblasts newly isolated from Fst/1 ${ }^{+/-}$and WT mice $14 \mathrm{~d}$ after saline or bleomycin treatment. Representative images of the staining are shown ( $n=5$ per group). Arrows indicate myofibroblasts with $\alpha$-SMA- and vimentin-positive staining. Nuclear, DAPI. (A and F) Bars, $100 \mu \mathrm{m}$. (G) Quantification of F presents percentage of $\alpha$-SMA-positive cells (myofibroblasts). **, $\mathrm{P}<0.01$. (H) Western blot analysis of $\alpha$-SMA in cell extracts (Cell), type I collagen (Col1), and fibronectin (Fn1) in the medium (supernatant [SN]) of primary cultured lung fibroblasts newly isolated from Fst/1 $1^{+-}$and WT mice $14 \mathrm{~d}$ after bleomycin treatment ( $n=6$ per group). (C and $\mathrm{H}$ ) $\beta$-Actin was used as a loading control. (A-D, F, and $H)$ The experiments were performed three times. $(B, D$, and $G)$ Error bars indicate mean $\pm S E M$.

in the lower plate, we found that injured AECs isolated from WT mice $7 \mathrm{~d}$ after bleomycin treatment promoted the activation of WT fibroblasts, as determined by the increased protein levels of $\alpha$-SMA and subsequent ECM production (type I collagen and fibronectin). Fstl1 $1^{+/-}$AECs demonstrated reduced capacity to activate fibroblasts relative to WT AECs (Fig. 5 F). In addition, Fst $11^{+/-}$fibroblasts had reduced response to both WT and Fstl1 ${ }^{+-}$injured epithelial cells (Fig. 5 F), suggesting the involvement of Fstl1 in epithelial-mesenchymal communication. Furthermore, co-culturing of AECs directly with fibroblasts gave similar results (Fig. 5 G). Collectively, these data suggest that Fstl1 has a significant role in transmitting pro-fibrotic signals between AECs and fibroblasts.
Fstl 1 modulates epithelial injury by facilitating TGF- $\beta 1$ signaling but antagonizing BMP4 signaling in epithelial cells Both TGF- $\beta$ and BMP signaling have been shown to have a role in lung fibrogenesis. Furthermore, the TGF- $\beta$ and BMP signaling balance is crucial for lung homeostasis and is significantly disrupted in pulmonary fibrosis (Shannon and Hyatt, 2004; Gauldie et al., 2007). To determine the molecular mechanism whereby the absence of Fstl1 activity results in the protection against epithelial injury described above, we examined Smad-mediated TGF- $\beta$ /BMP signaling in lung tissues $14 \mathrm{~d}$ after bleomycin treatment. Western blotting using lung extracts showed higher phosphorylation levels of Smad1 in Fstl1 ${ }^{+/-}$lungs (Fig. 6 A), which is 

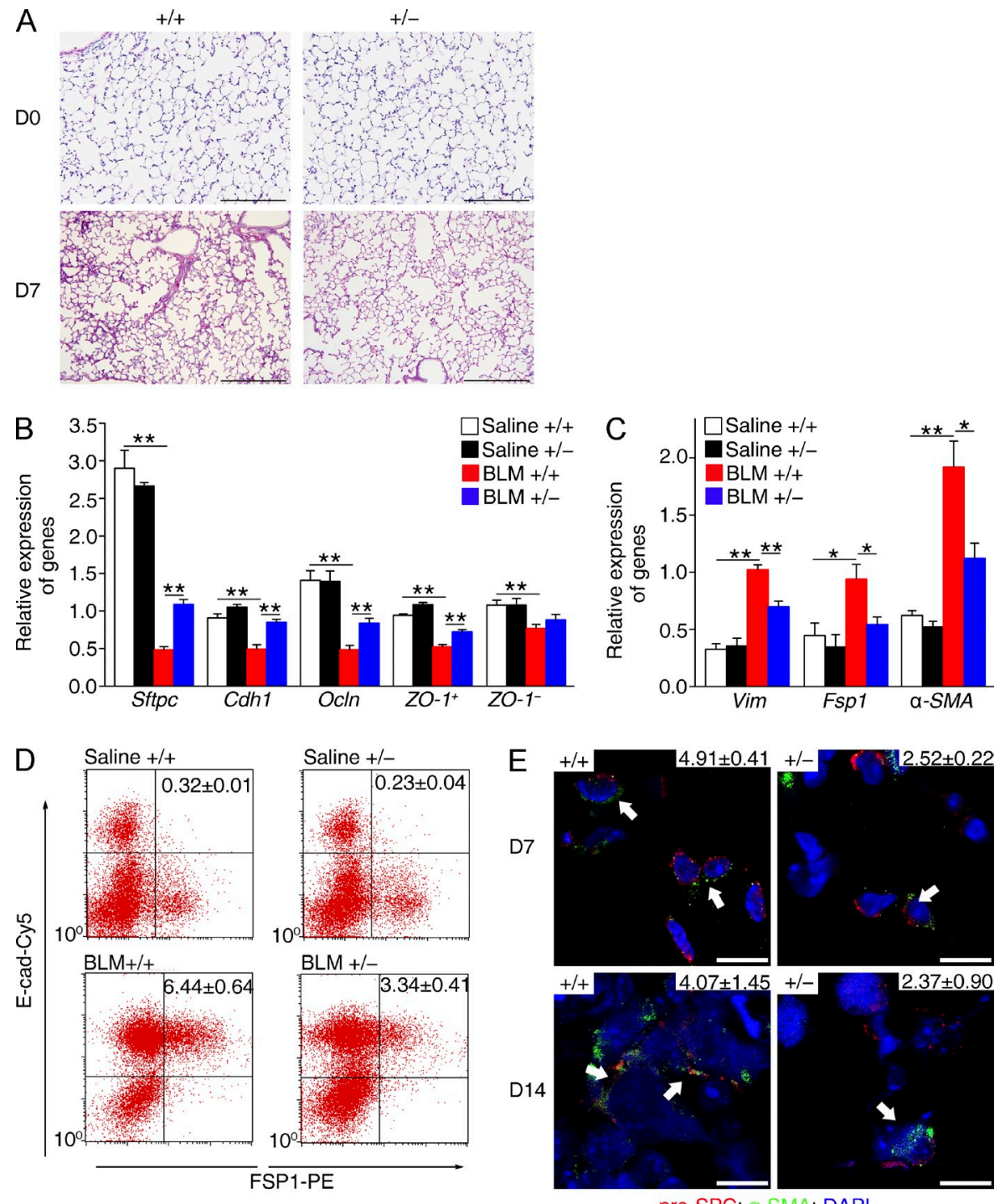

pro-SPC; a-SMA; DAPI

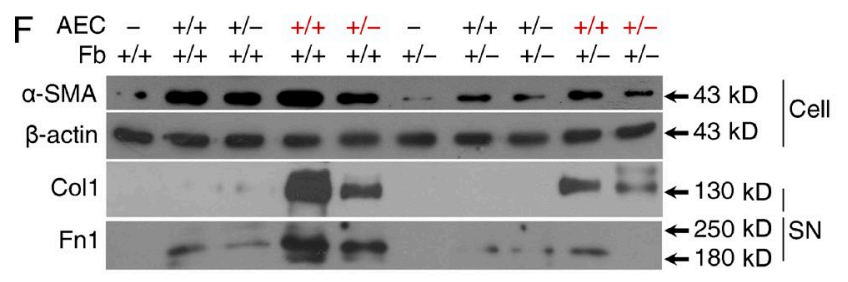

G AEC - +/t +/ $+1++/-\quad-\quad+/+\quad+/-\quad+/++/-$

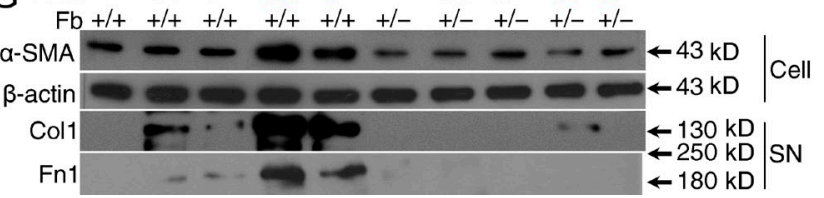

in agreement with our recent study that Fstl1 functions as a BMP4 antagonist to negatively regulate BMP4 signaling during embryonic lung development (Geng et al., 2011). In contrast, phosphorylation levels of $\mathrm{Smad} 2 / 3$ were lower in Fstl1 ${ }^{+/-}$lungs than those from their WT controls (Fig. $6 \mathrm{~A}$ ),
Figure 5. Fst/1 deficiency protects epithelial cells from injury. (A) Lung sections of Fst $/ 1^{+/-}$and their WT littermates treated with $2.5 \mathrm{U} / \mathrm{kg}$ bleomycin for $7 \mathrm{~d}$ were stained with hematoxylin and eosin. Representative images of the staining are shown ( $n=7$ per group). ( $B$ and $C$ ) Primary AECs were isolated from Fst $/ 1^{+/}$and WT littermates $7 \mathrm{~d}$ after saline or $2.5 \mathrm{U} / \mathrm{kg}$ bleomycin treatment $(\mathrm{BLM} ; n=5$ per group). After 2-d culture, mRNA expression levels of epithelial cell markers including Sftpc, E-cadherin (Cdh1), Occludin (Oc/n), ZO- $1^{+}$, and ZO-1- (B) and mesenchymal cell markers including vimentin (Vim), Fsp 1, and $\alpha$-SMA (C) in AECs were assessed by qRT-PCR ${ }^{*}, \mathrm{P}<0.05 ;{ }^{* *}, \mathrm{P}<0.01$. Error bars indicate mean \pm SEM. (D) Representative flow cytometry plots of E-cadherin (E-cad)- and FSP1positive populations in newly isolated AECS from Fst/1 ${ }^{+/-}$and WT littermates $7 \mathrm{~d}$ after saline or $2.5 \mathrm{U} / \mathrm{kg}$ bleomycin treatment $(n=5$ per group). The percentage of E-cad ${ }^{+} \mathrm{FSP} 1^{+}$ AECs is indicated on the top right corner of each diagram. (E) Lung sections of Fst/1+/and WT littermates 7 and $14 \mathrm{~d}$ after $2.5 \mathrm{U} / \mathrm{kg}$ bleomycin treatment were immunostained with pro-SPC, $\alpha-S M A$, and DAPI as nuclear. Representative images of the staining are shown ( $n=6$ per group). Several pro-SPC $\alpha-$ $\mathrm{SMA}^{+} \mathrm{AEC}$ are shown (arrows). The percentage of pro-SPC+ $\alpha-S M A^{+}$AECs is presented on the top right corner of each diagram. Bars: (A) $100 \mu \mathrm{m}$; (E) $25 \mu \mathrm{m}$. (F and G) Primary AECs were newly isolated from Fst/1+/- and WT littermates $7 \mathrm{~d}$ after saline (black) or $2.5 \mathrm{U} / \mathrm{kg}$ bleomycin (red) treatment ( $n=4$ per group). Primary lung fibroblasts $(\mathrm{Fb})$ were newly isolated from untreated Fst/1 ${ }^{+/-}$and WT mice ( $n=4$ per group). (F) After 2-d culture, AECs in the upper chamber were co-cultured with fibroblasts in the lower plate of the transwell for 24 h. (G) AECs directly co-cultured with fibroblasts $(\mathrm{AEC} / \mathrm{Fb}=1: 10)$ for $48 \mathrm{~h}$. Protein expression levels of $\alpha$-SMA in cell extracts (Cell), type I collagen (Col1), and fibronectin (Fn1) in medium (supernatant [SN]) of lung fibroblasts were assessed by Western blot. $\beta$-Actin was used as a loading control. (A-G) The experiments were performed three times. suggesting that the restored TGF- $\beta$ /BMP balance may be the molecular underpinnings for the attenuated fibrogenesis in Fstl1 ${ }^{+/-}$mice. Furthermore, Western blotting using primary AECs isolated from $\mathrm{Fstl}_{\mathrm{f}} \mathrm{C}^{+-}$lungs $14 \mathrm{~d}$ after bleomycin treatment confirmed the restored TGF- $\beta / B M P$ 

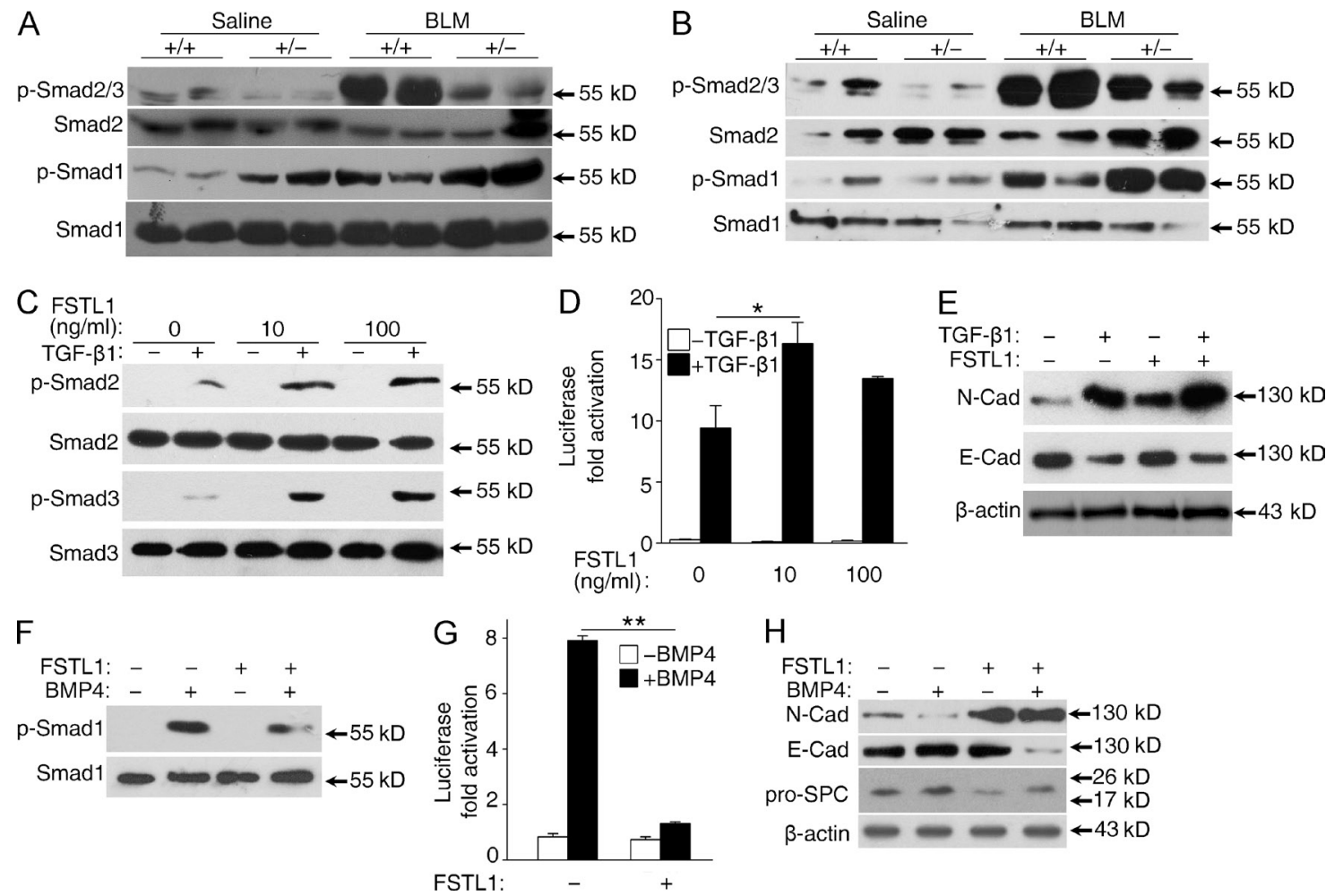

Figure 6. Fstl1 modulates epithelial injury by facilitating TGF- $\beta 1$ signaling but antagonizing BMP4 signaling in epithelial cells. (A and B) Western blot analysis of $\mathrm{p}-\mathrm{Smad} 2 / 3, \mathrm{Smad} 2, \mathrm{p}-\mathrm{Smad} 1$, and Smad 1 in lung tissues (A) and newly isolated primary AECs (B) from Fst/1+/and WT littermates $14 \mathrm{~d}$ after saline or $2.5 \mathrm{U} / \mathrm{kg}$ bleomycin (BLM) treatment ( $n=4$ per group). (C) A549 cells were treated with $5 \mathrm{ng} / \mathrm{ml}$ TGF- $\beta 1$ and 10 or $100 \mathrm{ng} / \mathrm{ml}$ FSTL1 for $30 \mathrm{~min}$. p-Smad2, Smad2, p-Smad3, and Smad3 were analyzed by Western blot analysis. (D) A549 cells transfected with CAGA-luciferase reporter were treated with $5 \mathrm{ng} / \mathrm{ml} \mathrm{TGF-} \beta 1$ and 10 or $100 \mathrm{ng} / \mathrm{ml} \mathrm{FSTL1} \mathrm{for} 16 \mathrm{~h}$. Cells were harvested for luciferase assay. ${ }^{*}$, P< 0.05 . (E) A549 cells were treated with $5 \mathrm{ng} / \mathrm{ml}$ TGF- $\beta 1$ and $100 \mathrm{ng} / \mathrm{ml} \mathrm{FSTL1}$ for $48 \mathrm{~h}$. Cells were extracted for Western blot analysis of N-cadherin (N-cad) and E-cadherin (E-cad). (F) A549 cells were treated with $20 \mathrm{ng} / \mathrm{ml} \mathrm{BMP4}$ and $100 \mathrm{ng} / \mathrm{ml}$ FSTL1 for $30 \mathrm{~min}$. p-Smad1 and Smad $1 \mathrm{were}$ analyzed by Western blot analysis. (G) A549 cells transfected with BRE-luciferase reporter were treated with $20 \mathrm{ng} / \mathrm{ml} \mathrm{BMP4}$ and $100 \mathrm{ng} / \mathrm{ml}$ FSTL1 for $16 \mathrm{~h}$. Cells were harvested for luciferase assay. ${ }^{*}, \mathrm{P}<0.01$. (H) A549 cells were treated with $20 \mathrm{ng} / \mathrm{ml} \mathrm{BMP4}$ and $100 \mathrm{ng} / \mathrm{ml} \mathrm{FSTL1}$ for $48 \mathrm{~h}$. Cells were extracted for Western blot analysis of N-cadherin, E-cadherin, and pro-SPC. (E and H) $\beta$-Actin was used as a loading control. (A-H) The experiments were performed three times. (D and G) Error bars indicate mean \pm SEM.

balance in lung epithelial cells (Fig. 6 B). These data suggest that Fstl1 deficiency protects epithelial cells from injury by restoring TGF- $\beta$ /BMP balance in epithelium and that Fstl1 mediates the epithelial injury by its opposing effects on TGF- $\beta$ / BMP signaling.

We then performed gain of function experiments by administration of recombinant FSTL1 protein to the A549 lung epithelial cell line. As shown in Fig. $6(\mathrm{C}-\mathrm{H})$, FSTL1 recombinant protein promoted TGF- $\beta 1$ signaling, as indicated by the increased phosphorylation of $S m a d 2 / 3$ and activity of the reporter CAGA-luciferase, but antagonized BMP4 signaling, as indicated by the decreased phosphorylation of Smad1 and activity of the reporter BMP-responsive element (BRE)-luciferase, leading to the increased expression of $\mathrm{N}$-cadherin and decreased expression of E-cadherin. These data support a critical role of Fstl1 in modulating TGF- $\beta$ /BMP signaling balance, which may account for the in vivo effects on fibrosis.
FSTL1 modulates myofibroblast activation by facilitating TGF- $\beta 1$ signaling in a BMP4-independent manner

To further define the impact of Fstl1 deficiency on myofibroblast accumulation, we isolated primary fibroblasts $14 \mathrm{~d}$ after bleomycin treatment and measured Smad-mediated TGF- $\beta$ / BMP signaling. As expected, bleomycin-increased phosphorylation and nuclear accumulation of Smad2/3 in WT fibroblasts were attenuated in Fstl1 ${ }^{+-}$fibroblasts (Fig. 7, A and B). However, lung fibroblasts isolated from WT and $\mathrm{Fstl}^{+/-}$mice displayed similar phosphorylation and nuclear accumulation of Smad1 (Fig. 7, A and B). This is in agreement with the recent study in which the canonical BMP pathway is reactivated mainly in lung epithelium and much less in mesenchyme after lung injury (Sountoulidis et al., 2012). These data indicate that FSTL1 modulates TGF- $\beta 1$ signaling in lung fibroblasts in a BMP4-independent manner. Moreover, WT and Fstl1 $1^{+/}$mice displayed comparable mRNA and active protein levels of TGF- $\beta 1$ (Fig. 7, C and D) and BMP4 (Fig. 7, 
$\mathrm{E}$ and F) with/without bleomycin treatment, supporting the role of FSTL1 in TGF- $\beta / \mathrm{BMP} / \mathrm{Smad}$ signaling in vivo but not their expression and activation.

\section{FSTL1 binds to TGF- $\beta 1$ and positively regulates Smad signaling in vitro}

To determine the molecular mechanisms whereby FSTL1 promotes TGF- $\beta 1 / \operatorname{Smad} 2 / 3$ signaling described above, recombinant FSTL1 protein was added to TGF- $\beta 1-$ treated primary cultures of lung fibroblasts. TGF- $\beta 1$ treatment induced expression and secretion of FSTL1 in fibroblasts in a timedependent manner (Fig. 8 A). FSTL1 addition promoted TGF- $\beta 1$-induced phosphorylation of Smad2/3, protein expression of $\alpha$-SMA, and production of type I collagen and fibronectin (Fig. 8, B and C). Meanwhile, FSTL1-deficient fibroblasts showed blunted TGF- $\beta 1$-induced phosphorylation of Smad2/3, protein expression of $\alpha$-SMA, and production of type I collagen and fibronectin (Fig. 8, D-F). Blockade of activated Smad2/3 signaling with SB525334, a selective inhibitor of ALK5, significantly inhibited TGF- $\beta 1 /$ FSTL1-mediated $\alpha$-SMA expression and ECM production in fibroblasts (Fig. $8 \mathrm{G}$ ). These data suggest that Fstl1 promotes myofibroblast activation and accumulation through its positive role in facilitating TGF- $\beta 1 /$ Smad $2 / 3$ signaling.

As FSTL1 is a secreted protein, we reasoned that it should function at the ligand/receptor level. To test this possibility, we used constitutively active TGF- $\beta$ type I receptors (caALK4 and caALK5), which can activate Smad2/3 independently of ligands and type II receptors. Overexpression of Fstl1 did not promote caALK4/5-induced activation of CAGA-luciferase (Fig. $8 \mathrm{H}$ ) in Hep3B cells, suggesting that Fstl1 acts upstream of TGF- $\beta$ type I receptors. Our previous study reported a weak affinity of FSTL1 to TGF- $\beta 1\left(K_{d}=36 \mathrm{nM}\right.$; Geng et al., 2011). Binding experiments confirmed that FSTL1 directly binds TGF- $\beta 1$ or its type II receptor (T $\beta$ RII; Fig. 8, I and J) but not the type I receptor (T $\beta R \mathrm{I}$; Fig. $8 \mathrm{~K}$ ). The binding of FSTL1 to TGF- $\beta 1$ facilitated presentation of TGF- $\beta 1$ to the T $\beta$ RII (Fig. 8 L). Collectively, these results suggest a role for FSTL1 in myofibroblast activation and fibrogenesis through the interactions with the TGF- $\beta 1$-receptor complex and regulating the downstream $\mathrm{Smad} 2 / 3$ signaling.

\section{Blockage of FSTL1 with a neutralizing antibody attenuates bleomycin-induced lung fibrosis in vivo}

These data demonstrate a profibrotic role for endogenous FSTL1 in bleomycin-induced lung fibrosis. We then reasoned that blocking FSTL1 signaling with a neutralizing antibody would alleviate fibrotic response. To this end, we generated mAbs against two mixed recombinant fractions of mouse FSTL1 protein and selected one clone (22B6) for further neutralizing antibody study. The antibody was able to inhibit TGF- $\beta 1$-induced mRNA expression of Col1a1 (Fig. S1 A) and fibronectin (Fn1) in primary lung fibroblasts (Fig. S1 B). The binding affinity of 22B6 mAb to FSTL1 was determined by surface plasmon resonance (SPR) analysis. Kinetic measurements using different concentrations of FSTL1 protein
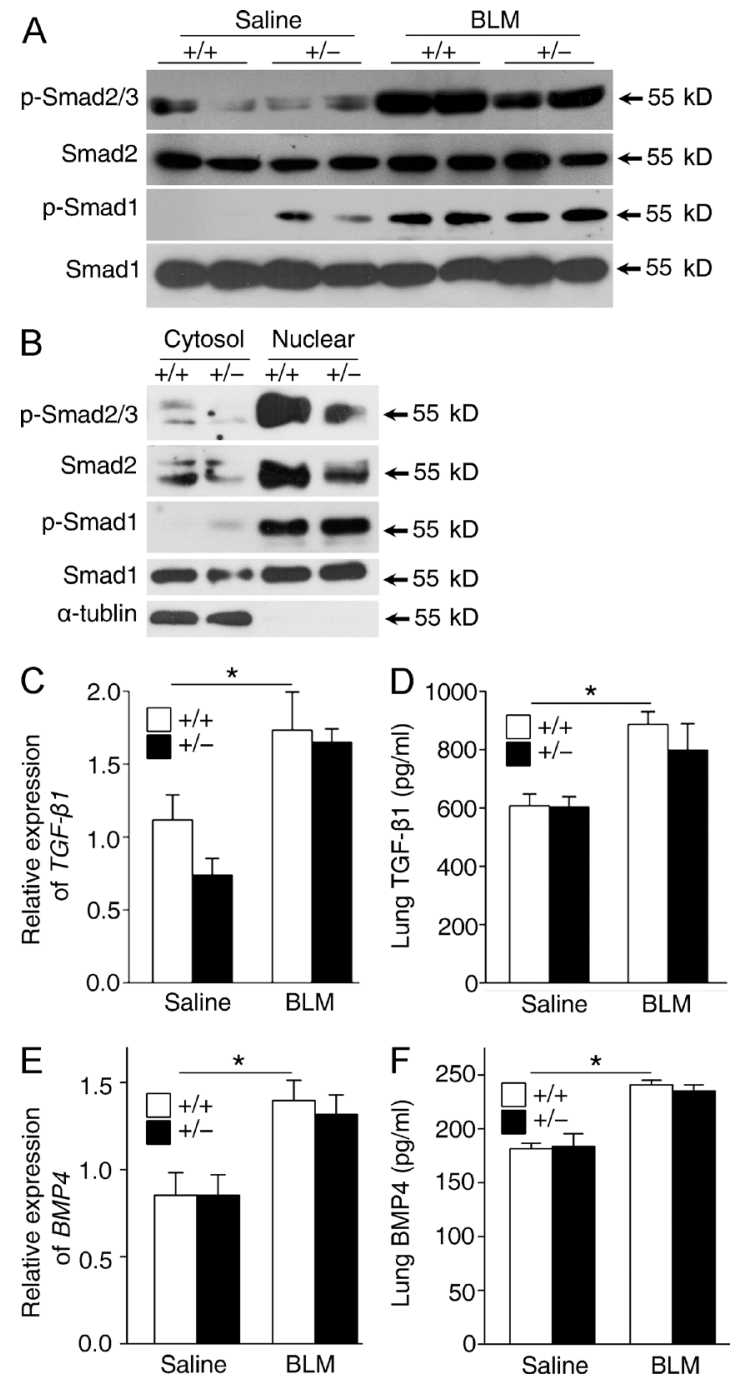

Figure 7. Fstl1 modulates TGF- $\beta 1$ but not BMP4 signaling in lung fibroblasts. (A and B) Primary lung fibroblasts were newly isolated from Fst $11^{+/-}$mice and their WT littermates $14 \mathrm{~d}$ after saline or bleomycin (BLM) treatment ( $n=4$ per group). Western blots of $p-S m a d 2 / 3, S m a d 2$, $\mathrm{p}$-Samd1, and Smad1 in fibroblasts (A) and cytosolic (Cytosol) and nuclear (Nuclear) fractions (B) of fibroblasts. $\alpha$-Tubulin was used as a control for cytosolic fractions. (C-F) Fst/1 ${ }^{+/-}$and WT littermates were treated with saline or $2.5 \mathrm{U} / \mathrm{kg}$ bleomycin for $14 \mathrm{~d}$ ( $n=5$ per group). (C) qRT-PCR analysis of TGF- $\beta 1$ mRNA expression in lung tissues. (D) ELISA analysis of active form of TGF- $\beta 1$ protein in lung tissues. (E) qRT-PCR analysis of BMP4 mRNA expression in lung tissues. (F) ELISA analysis of BMP4 protein in lung tissues. ${ }^{*}, \mathrm{P}<0.05$. (A-F) The experiments were performed three times. (C-F) Error bars indicate mean \pm SEM.

yielded a $K_{\mathrm{d}}$ of $26.9 \mathrm{nM}$ for 22B6 mAb (Fig. S1 C), but there was no binding of 22B6 mAb to follistatin (Fig. S1 D). Pulldown assay showed that 22B6 $\mathrm{mAb}$ recognized FSTL1 specifically, but it could not detect follistatin or TGF- $\beta 1$ (Fig. S1 E), confirming the high specific affinity of $22 \mathrm{~B} 6 \mathrm{mAb}$ to FSTL1. Biological assays revealed that the $22 \mathrm{~B} 6 \mathrm{mAb}$ blocked the ability of FSTL1 to induce the production of IL-6 in Cos7 cells (Fig. S1 F; Miyamae et al., 2006), to antagonize BMP4-induced 

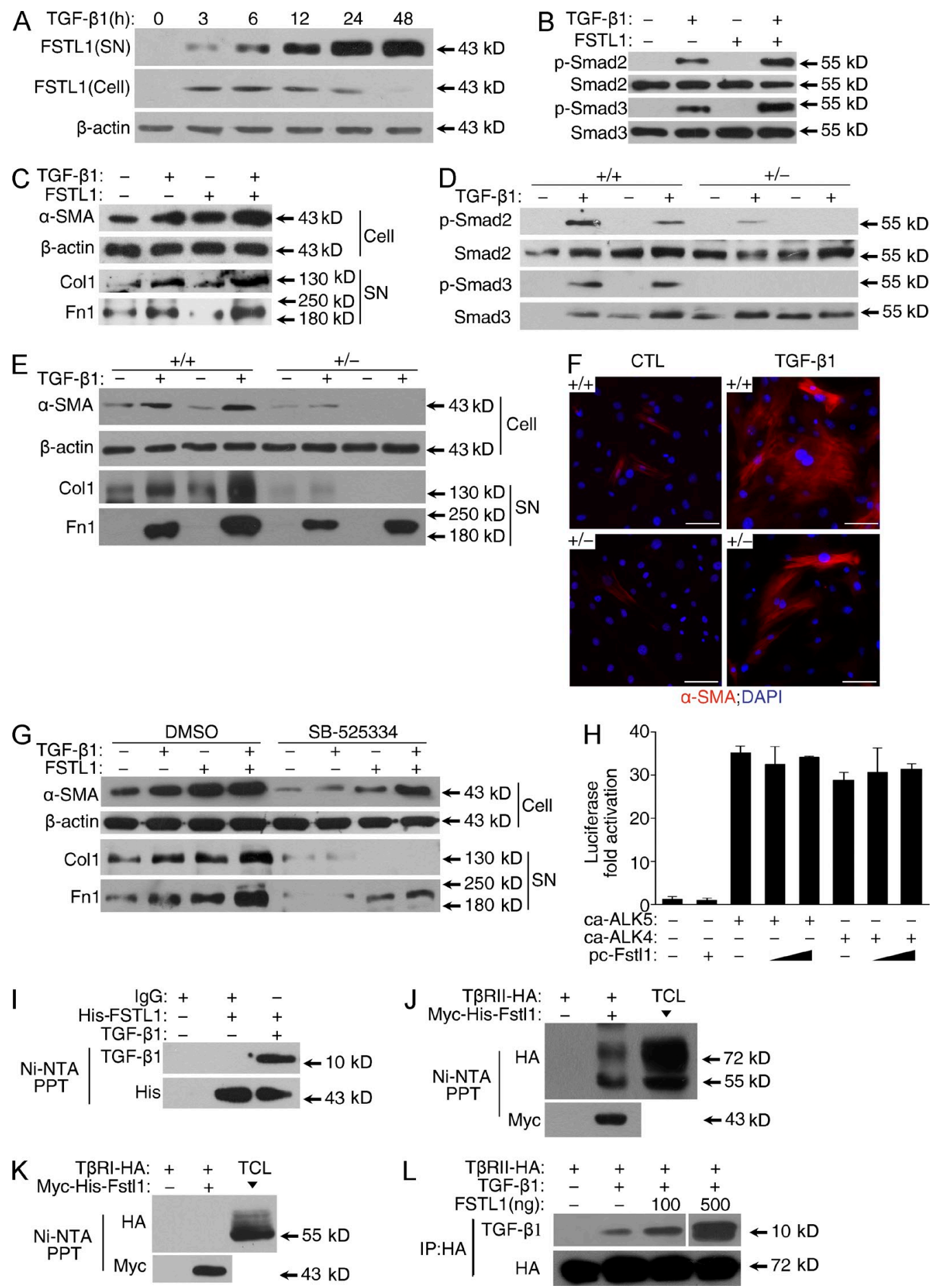

Figure 8. Fstl1 modulates myofibroblast differentiation by facilitating TGF- $\beta 1$ signaling. (A) Primary lung fibroblasts from C57BL/6J mice $(n=3)$ were treated with $5 \mathrm{ng} / \mathrm{ml} \mathrm{TGF}-\beta 1$ for the indicated time points. FSTL1 protein expression in conditioned medium (supernatant [SN]) or fibroblasts (Cell) was determined by Western blot. (B and C) Primary lung fibroblasts from C57BL/6J mice $(n=3)$ were treated with $5 \mathrm{ng} / \mathrm{ml}$ TGF- $\beta 1 \mathrm{and} 100 \mathrm{ng} / \mathrm{ml}$ FSTL1. (B) p-Smad2, Smad2, p-Smad3, and Smad3 were analyzed by Western blot 30 min after TGF- $\beta 1$ treatment. (C) Protein expressions of $\alpha$-SMA in cell extracts (Cell), type I collagen (Col1), and fibronectin (Fn1) in medium (supernatant) were determined by Western blot $24 \mathrm{~h}$ after TGF- $\beta 1$ treatment. (D-F) Primary lung fibroblasts from Fst $11^{+/-}$mice and WT littermates ( $n=5$ per group) were treated with $5 \mathrm{ng} / \mathrm{ml}$ TGF- $\beta 1$. (D) p-Smad2, Smad2, p-Smad3, and Smad3 were analyzed by Western blot 30 min after TGF- $\beta 1$ treatment. (E) Protein expressions of $\alpha$-SMA in cell extracts (Cell), type I collagen (Col1), and fibronectin (Fn1) in medium (supernatant) were detected by Western blot $24 \mathrm{~h}$ after TGF- $\beta 1$ treatment. (F) Immunofluorescence staining of polymerized $\alpha$-actin stress fibers (nucleus, DAPI) $24 \mathrm{~h}$ after TGF- $\beta 1$ treatment. Representative images of the staining are shown. Bars, $100 \mu \mathrm{m}$. (G) Primary lung fibroblasts from C57BL/6J mice $(n=3)$ were pretreated with DMSO and $10 \mu \mathrm{M}$ SB-525334 for $1 \mathrm{~h}$ and then treated with $5 \mathrm{ng} / \mathrm{ml}$ TGF- $\beta 1$ and $100 \mathrm{ng} / \mathrm{ml}$ FSTL1 for $24 \mathrm{~h}$. Protein expressions of $\alpha$-SMA 
SFTPC expression in A549 cells (Fig. S1 G; Geng et al., 2011), and to attenuate hypertrophic actions to phenylephrine (PE) treatment in cultured cardiac myocytes (Fig. S1, H and I; Shimano et al., 2011). These data suggest 22B6 mAb to FSTL1 was biologically active in these in vitro assays.

We further analyzed the blocking capability of 22B6 mAb on FSTL1-promoted TGF- $\beta$ responsiveness in fibroblasts. Primary cultured lung fibroblasts were administrated with either antibody (22B6) or isotype control antibody (IgG1), followed by TGF- $\beta 1$ treatment. FSTL1 has been shown to be induced by TGF- $\beta 1$ and to promote TGF- $\beta$ responsiveness in an autocrine manner in fibroblasts (Fig. 8,A-G). As expected, neutralizing FSTL1 with 22B6 mAb decreased FSTL1promoted TGF- $\beta 1$-induced $\alpha$-SMA expression and ECM production in fibroblasts (Fig. $9 \mathrm{~A}$ ), accompanied by much lower phosphorylation of Smad2/3 (Fig. 9 B). We further used 22B6 $\mathrm{mAb}$ to treat primary lung fibroblasts isolated from patients with IPF. As shown in Fig. 9 C, antibody (22B6) administration resulted in a significant inhibition of basal or TGF- $\beta 1$-induced $\alpha$-SMA expression and ECM production in $2 / 2$ patient samples, suggesting that $22 \mathrm{~B} 6 \mathrm{mAb}$ could recognize both human and murine FSTL1 based on their protein similarity $(>92 \%$ sequence identity; Zwijsen et al., 1994).

To define whether 22B6 mAb blocks FSTL1-mediated epithelial-mesenchymal communication, we performed coculture transwell assay. Primary lung AECs in the upper chamber were pretreated with $22 \mathrm{~B} 6 \mathrm{mAb}$ or anti-TGF- $\beta 1 \mathrm{mAb}$, followed by TGF- $\beta 1$ or FSTL1 treatment, respectively. Then the upper chamber was inserted back into the lower plate of the transwell. The activation of fibroblasts cultured in the lower plate was measured after 24-h epithelial-mesenchymal coculture (Fig. 9 D). As shown in Fig. 9 (E-G), TGF- $\beta 1-$ activated AECs promoted the activation of underlying fibroblasts, as determined by the increased mRNA levels of $\boldsymbol{\alpha}$-SMA, type I collagen (Col1a1), and fibronectin (Fn1) in fibroblasts upon 24-h coincubation. FSTL1 increased TGF- $\beta 1$-induced AEC activation and subsequent fibroblast activation. As expected, anti-TGF- $\beta 1 \mathrm{mAb}$ blocked TGF- $\beta 1$ activity and inhibited subsequent fibroblast activation. Notably, 22B6 $\mathrm{mAb}$ had less effect on TGF- $\beta 1$ activity, but blocked FSTL1-promoted TGF- $\beta 1$ activity. In addition, transwell co-culture assay showed that 22B6 mAb blocked the antagonizing ability of FSTL1 on BMP4 during epithelial-mesenchymal communication (Fig. $9 \mathrm{H}$ ). Collectively, our data demonstrate that neutralizing FSTL1 with 22B6 mAb inhibits FSTL1disrupted TGF- $\beta$ /BMP balance and moderates epithelialmesenchymal communication.

To determine the therapeutic impact of the administration of FSTL1-neutralizing antibody on lung fibrosis in vivo, we initially treated C57BL/6J mice with 22B6 mAb from day 5 to day 11 after bleomycin injury (Fig. 10 A). As shown in Fig. 10 B, collagen content was significantly decreased in the mice treated with FSTL1-neutralizing antibody, compared with those treated with isotype-matched control antibody. Masson's trichrome staining displayed a similar result (Fig. 10, C and D). We next asked whether $22 \mathrm{~B} 6 \mathrm{mAb}$ could prevent further progression of established fibrosis. We treated mice with bleomycin to establish lung fibrosis and with 22B6 $\mathrm{mAb}$ from day 8 to day 17 after bleomycin injury (Fig. $10 \mathrm{E}$ ). 22B6 mAb significantly reduced lung fibrosis even after fibrotic disease had been established (Fig. 10, F-H). These data further support the concept that the endogenous production of FSTL1 after noninfectious lung injury regulates the fibroproliferative response. Collectively, our data demonstrate that FSTL1 plays a key role in fibrogenesis through regulating TGF- $\beta 1-$ mediated myofibroblast accumulation and ECM production. As a proof of principle, antibodymediated neutralization of FSTL1 significantly attenuated TGF- $\beta 1$-induced myofibroblast differentiation and ECM production in fibroblasts in vitro and bleomycin-induced lung fibrosis in mice in vivo. These data are encouraging that blockade of FSTL1 would be an attractive strategy for patients with progressive pulmonary fibrosis.

\section{DISCUSSION}

IPF is a refractory disease and most patients deteriorate with a median survival of $<3 \mathrm{yr}$ from diagnosis. More effective therapies are needed, and one of the hurdles to developing therapeutics is lack of complete understanding of the molecular mechanisms underlying pathogenesis of the disease (ATS/ ERS, 2000; King et al., 2011). The findings reported here add new insights into our understanding of the regulation of pulmonary fibrogenesis and demonstrate a novel role of FSTL1 in promoting fibrosis. We provide data at the cellular, molecular, and animal levels, as well as proof of principle intervention data to support a role of FSTL1 as a therapeutic target for lung fibrosis.

in cell extracts (Cell), type I collagen (Col1), and fibronectin (Fn1) in medium (supernatant) were detected by Western blot. (A-E and G) $\beta$-Actin was used as a loading control. (H) Hep3B cells were cotransfected with CAGA-luciferase reporter, ca-ALK4, ca-ALK5, and pc-Fstl 1 for 36 h. Cells were lysed for luciferase assay, and the data were normalized to Renilla activity. Error bars indicate mean \pm SEM. (I) His-tagged FSTL1 and TGF- $\beta 1$ protein complex was pulled down using Ni-NTA agarose and then subjected to Western blot analyses with anti-TGF- $\beta 1$ antibody to confirm the presence of TGF- $\beta 1$ (top). The presence of FSTL1 was detected with anti-His antibody (bottom). Unspecific lgG antibodies were used as a control. (J and K) HEK293 cells were transfected with Myc-

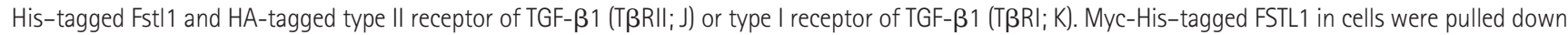
using Ni-NTA agarose and then subjected to Western blot analyses with anti-HA antibody to confirm the presence of T $\beta R I I(J)$ or T $\beta R I$ (K; top). The presence of FSTL1 was detected with anti-Myc antibody (bottom). TCL, total cell lysates. (L) COS-7 cells were transfected with HA-tagged T $\beta R I I$. T $\beta R$ RII-HA was immunoprecipitated with HA-agarose and incubated with $100 \mathrm{ng}$ TGF- $\beta 1$ and 100 or $500 \mathrm{ng}$ FSTL1 protein. TGF- $\beta 1$ and T $\beta R \|$ were detected with anti-TGF- $\beta 1$ and anti-HA antibodies, respectively. The white line indicates intervening lanes have been spliced out. (A-L) The experiments were performed three times. 

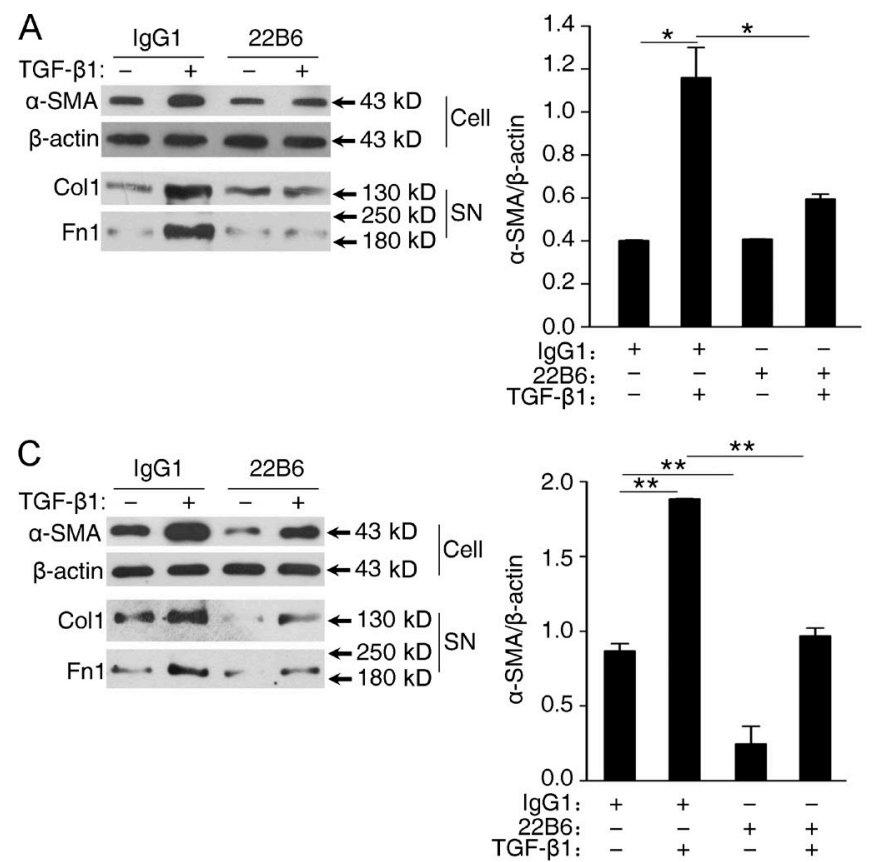

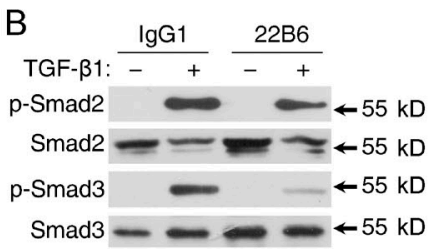

D

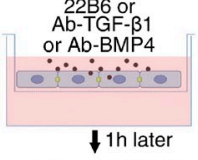
FSTL1 or TGF- $\beta 1$ or BMP4

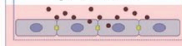

124h later

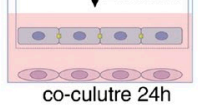

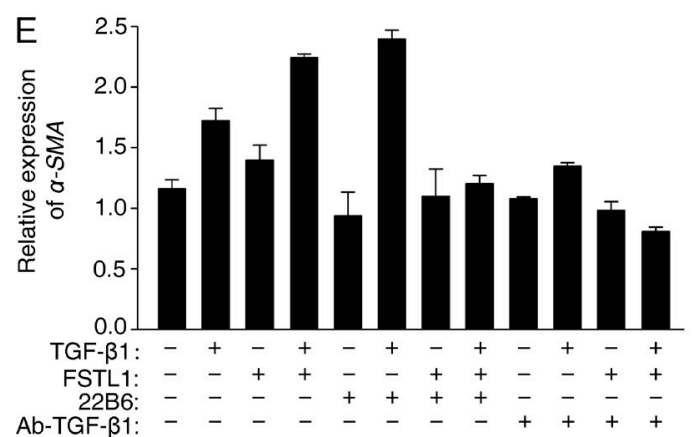
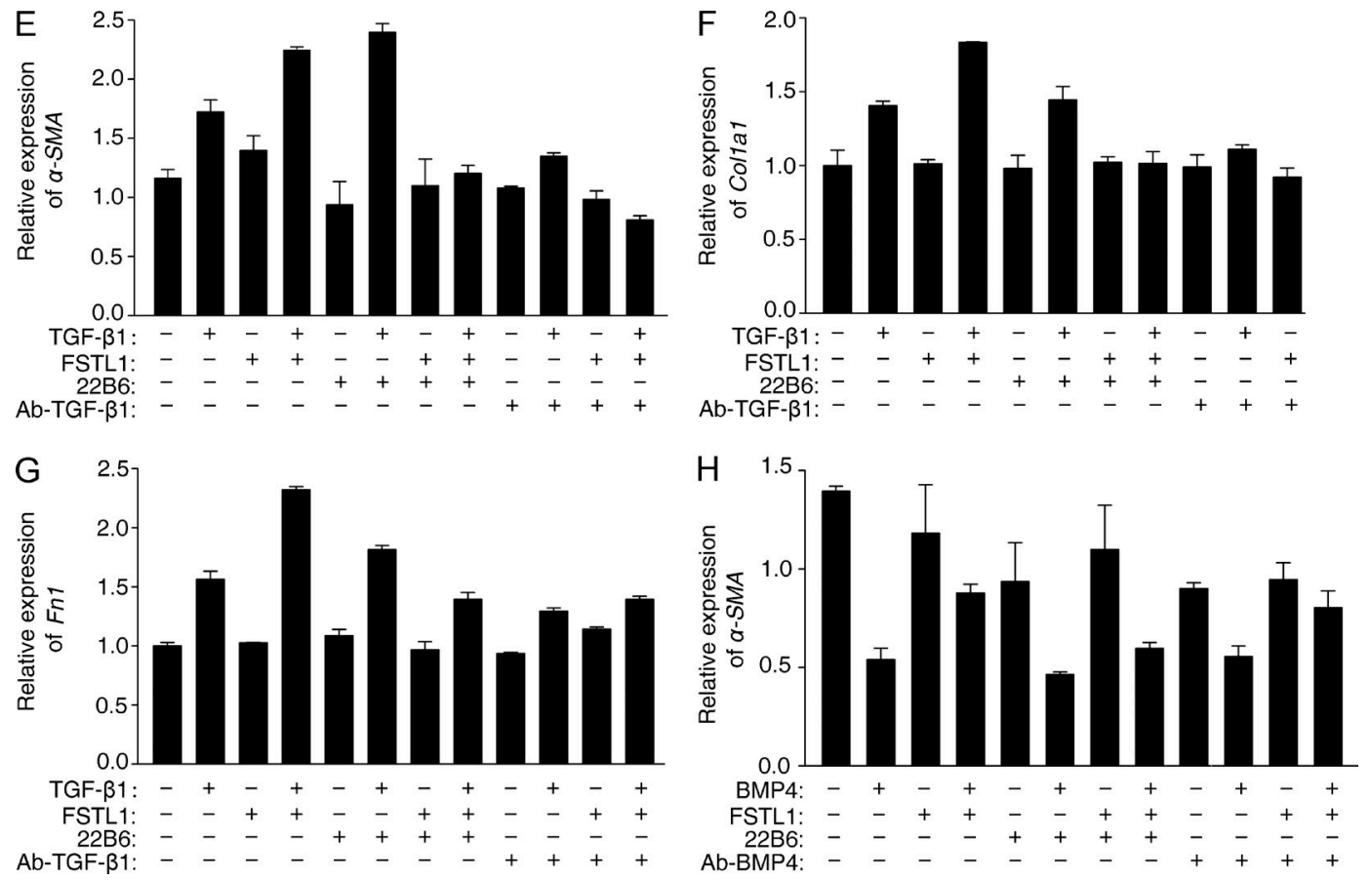

Figure 9. FSTL1-neutralizing antibody attenuates TGF- $\beta 1$ responsiveness in primary lung fibroblasts. (A-C) Primary lung fibroblasts from C57BL/6J mice ( $n=3$; A and B) or from IPF patients $(n=2 ; \mathrm{C})$ were treated with $1 \mu \mathrm{g} / \mathrm{ml} \mathrm{FSTL1-neutralizing} \mathrm{antibodies} \mathrm{(22B6)} \mathrm{or} \mathrm{control} \mathrm{lgG1} 1 \mathrm{~h}$ before $5 \mathrm{ng} / \mathrm{ml} \mathrm{TGF}-\beta 1$ treatment. (A and C) $24 \mathrm{~h}$ after TGF- $\beta 1$ treatment, Western blot analysis of $\alpha$-SMA in cell extracts (Cell), type I collagen (Col1), and fibronectin (Fn1) in the medium (supernatant [SN]) was performed. $\beta$-Actin was used as a loading control. Relative density of the bands of $\alpha$-SMA normalized to $\beta$-actin is represented in the graphs. ${ }^{*}, P<0.05 ;{ }^{* *}, P<0.01$. (B) 30 min after TGF- $\beta 1$ treatment, Western blot analysis of $p-S m a d 2, S m a d 2, p-S m a d 3$, and Smad3. (D) Schematic of experimental design of E-H: AECs and lung fibroblasts were isolated from C57BL/6J mice $(n=5)$ and cultured in the upper chamber or lower plate of a transwell, respectively. After 2 - $d$ culture, AECs in the upper chamber were pretreated with $1 \mu \mathrm{g} / \mathrm{ml} 22 \mathrm{~B} 6 \mathrm{mAb}$ or TGF- $\beta 1-$ neutralizing antibodies (Ab-TGF- $\beta 1$; E-G) or BMP4-neutralizing antibodies (Ab-BMP4; H) for $1 \mathrm{~h}$ and then treated with $100 \mathrm{ng} / \mathrm{ml} \mathrm{FSTL1} \mathrm{or} 5 \mathrm{ng} / \mathrm{ml}$ TGF- $\beta 1$ $(\mathrm{E}-\mathrm{G})$ or $20 \mathrm{ng} / \mathrm{ml} \mathrm{BMP4}(\mathrm{H})$ for $24 \mathrm{~h}$. After that, the upper chamber was inserted back to the lower plate, and AECs were co-cultured with fibroblasts for another $24 \mathrm{~h}$. (E-G) mRNA expression of $\alpha$-SMA (E), Col1a 1 (F), and fibronectin (Fn 1; G) after TGF- $\beta 1$ treatment in the fibroblasts was determined by qRT-PCR. (H) $\alpha$-SMA mRNA expression after BMP4 treatment in the C57BL/6J lung fibroblast was determined by qRT-PCR. (A and B and E-H) The experiments were performed three times. (C) The experiments were performed twice with similar results. $(A, C$, and $E-H)$ Error bars indicate mean \pm SEM. 
A

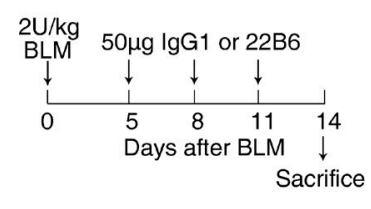

$\mathrm{E}$

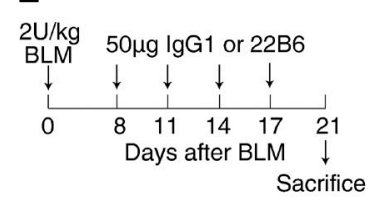

B

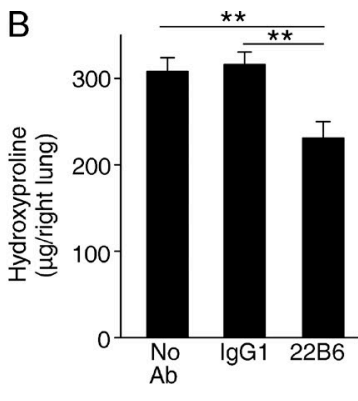

$\mathrm{F}$

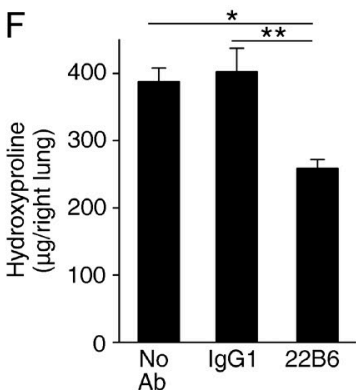

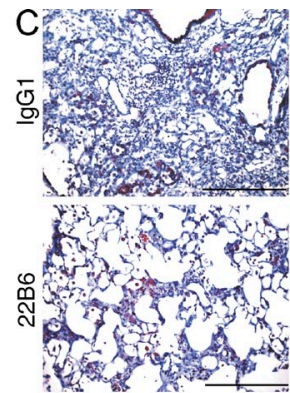
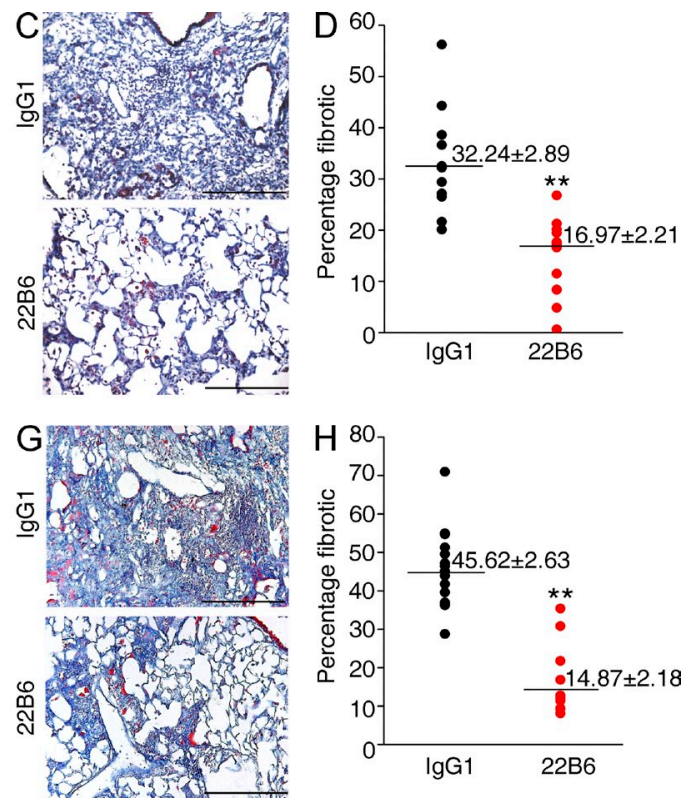

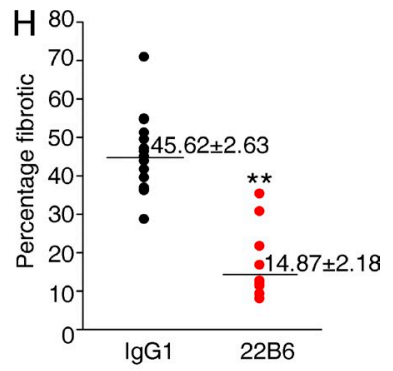

Figure 10. FSTL1-neutralizing antibody attenuates bleomycin-induced fibrosis in mice. (A) Intervention dosing regimen at the early stage of lung fibrosis model. C57BL/6J mice were intraperitoneally injected with FSTL1-neutralizing antibody (22B6 mAb) or isotype-matched control IgG1 (50 $\mathrm{mg} /$ mouse/time point; $n=12$ per group) on days 5,8 , and 11 after bleomycin treatment (BLM; $2 \mathrm{U} / \mathrm{kg})$, and lungs were harvested at day 14 for the following analyses. (B) Hydroxyproline contents in lung tissues. ${ }^{* *}, \mathrm{P}<0.01$. (C) Masson trichrome staining of collagen on lung sections. Representative images of the staining are shown. (D) Lung fibrotic score analysis of the lung sections. The fibrotic area is presented as a percentage. ${ }^{* *}, P=0.00004$. (E) Intervention dosing regimen at the late stage of lung fibrosis model. $\mathrm{C} 57 \mathrm{BL} / 6 \mathrm{~J}$ mice were intraperitoneal injected with $22 \mathrm{~B} 6 \mathrm{mAb}$ or $\operatorname{lgG} 1$ (50 $\mu \mathrm{g} /$ mouse/time point; $n=15$ per group) on days $8,11,14$, and 17 after bleomycin treatment ( $2 \mathrm{U} / \mathrm{kg})$, and lungs were harvested at day 21 for the following analyses. (F) Hydroxyproline contents in lung tissues. ${ }^{*}, P<0.05 ;{ }^{* *}, P<0.01$. (G) Masson trichrome staining of collagen on lung sections. Representative images of the staining are shown. ( $C$ and $G$ ) Bars, $100 \mu \mathrm{m}$. (H) Lung fibrotic score analysis of the lung sections. The fibrotic area is presented as a percentage. ${ }^{*}, \mathrm{P}=0.0000001 .(B, C, F$, and $G$ ) The experiments were performed three times. (B and $F)$ Error bars indicate mean \pm SEM. (D and H) Horizontal lines indicate mean.

We offered the following lines of evidence to demonstrate the profibrotic role of Fstl1 in pulmonary fibrogenesis. Targeting deletion of Fstl1 in mice significantly reduced alveolar injury and attenuated lung fibrosis after bleomycin injury. Fstl1 regulated activation of fibroblasts and differentiation of myofibroblasts and production of matrix proteins. Blockage of FSTL1 with a neutralizing antibody reduced bleomycin-induced fibrosis in mice in vivo. FSTL1 is a member of the secreted protein acidic rich in cysteines (SPARC) family (Bradshaw, 2012). It has been shown that follistatin blocked both activin and TGF- $\beta$ actions, leading to attenuated lung fibrosis in mice (Aoki et al., 2005). Unlike follistatin, FSTL1 shows more functional similarity to SPARC in promoting bleomycin-induced lung fibrosis (Trombetta-eSilva and Bradshaw, 2012).

We found that Fstl1 regulated lung fibrosis through (a) AEC injury, (b) epithelial-mesenchymal communication, and (c) fibroblast activation and differentiation. Our data demonstrate Fstl1 regulated epithelial cell injury, as deletion of Fstl1 significantly reduced alveolar damage. We further identified that Fstl1 regulates epithelial injury through modulating TGF- $\beta 1 /$ BMP signaling. Activation of TGF- $\beta 1$ (Sime et al., 1997; Munger et al., 1999; Zhao et al., 2002; Li et al., 2011) and inadequate BMP signaling (but not BMP expression;
Koli et al., 2006; Myllärniemi et al., 2008; Costello et al., 2010; Farkas et al., 2011) have been shown to play roles in regulating tissue fibrosis. In this study, we confirmed the ability of FSTL1 to negatively regulate BMP4 signaling, as we and others have shown in embryonic development (Geng et al., 2011; Xu et al., 2012). Moreover, we found positive regulation of FSTL1 on TGF- $\beta 1$ signaling. The dual role of FSTL1 in regulating TGF- $\beta$ and BMP4 signaling was further demonstrated in primary lung epithelial cells and cultured A549 cells, suggesting that FSTL1 disrupts TGF- $\beta$ /BMP balance by facilitating TGF- $\beta 1$ but inhibiting BMP4 signaling.

In fibroblast activation, Fstl 1 seems to promote TGF- $\beta 1$ signaling in a BMP4-independent manner. We found similarly reduced phosphorylation of $\operatorname{Smad} 2 / 3$ but comparable levels of phosphor-Smad1 in primary lung fibroblasts from bleomycin-injured $F_{s t l 1} 1^{+-}$lungs relative to WT, suggesting the function of FSTL1 is cell type dependent.

The current consensus suggests that IPF is initiated by repetitive microinjuries of AECs (Selman and Pardo, 2002), which subsequently provoke activation of fibroblasts and differentiation of myofibroblasts (Yang et al., 2013). Although several studies have shown evidence for epithelial-mesenchymal transition (EMT) by colocalization of epithelial and mesenchymal markers in IPF lungs and animal models (Kim et al., 
2006; Willis and Borok, 2007), a recent genetic tracing study argues against a role of EMT as a direct source of activated myofibroblasts in fibrotic lung (Rock et al., 2011). We identified a population of AECs containing both epithelial and mesenchymal markers in bleomycin-injured mouse lung. Meanwhile, we found that AECs from bleomycin-injured mice had decreased expression of epithelial markers and increased expression of mesenchymal markers. Furthermore, we found that these activated AECs could activate quiescent resident fibroblasts. Our study suggests a notion that expression of mesenchymal markers may simply reflect epithelial injury (Kage and Borok, 2012) and activation via aberrant epithelialmesenchymal communication (Selman and Pardo, 2002; Yang et al., 2013). In this study we prefer to use the term "epithelialmesenchymal communication" rather than EMT, as we suggest that FSTL1 in the matrix regulates epithelial-mesenchymal communication and enhances a fibrogenic milieu.

Strategies to target the TGF- $\beta 1$ signaling pathway have been developed for IPF. For example, a clinical trial of GC1008 (Grütter et al., 2008), a pan-specific fully human antiTGF- $\beta 1 \mathrm{mAb}$, is being developed in patients with IPF (du Bois, 2010). Owing to the pleiotropic nature of TGF- $\beta$, blocking TGF- $\beta$ signaling may also have adverse effects. Alternative strategies have been investigated. Integrin $\alpha v \beta 6$ binds and activates latent TGF- $\beta 1$, regulating pulmonary inflammation and fibrosis (Munger et al., 1999). A humanized $\mathrm{mAb}$ targeting integrin $\beta 6$ is now in clinical trial for patients with IPF (Horan et al., 2008). Connective tissue growth factor (CTGF), a downstream mediator of TGF- $\beta$, was able to confer susceptibility to bleomycin-induced fibrosis in the fibrosis-resistant BALB/c mouse strain (Bonniaud et al., 2004). A phase 2 trial of human neutralizing antibody against CTGF is under way to assess potential therapeutic benefits in patients with IPF (ClinicalTrials.gov identifier NCT01890265). Our findings suggest to us that blocking FSTL1 can be an alternative approach to interfere with TGF- $\beta 1 / \mathrm{BMP}$ signaling pathways for suppression of fibrogenesis. Our proof of principle neutralizing antibody experiments are encouraging. Because insufficiency of Fstl1 did not have much of an effect on immune response during injury, we think that FSTL1 modulates TGF- $\beta 1$ signaling at pathological conditions, not homeostatic functions, during lung injury and fibrosis. Therefore, inhibition of FSTL1 with neutralization antibody for IPF treatment may provide an advantage compared with block of TGF- $\beta 1$ or its receptors directly, similar to the situation with the antibodies to $\alpha v \beta 6$ integrin (Horan et al., 2008). Other approaches to block FSTL1-TGF- $\beta 1$ signaling such as mutant FSTL1 proteins are actively pursued in our laboratories.

In summary, we have demonstrated that FSTL1 plays an important role in bleomycin-induced pulmonary fibrosis and target deletion of Fstl1 attenuated the pulmonary fibrosis in response to noninfectious lung injury. We postulated that mechanisms of this action are through both protection against epithelial injury and impaired epithelial-mesenchymal communication, leading to limited myofibroblast expansion. FSTL1 exerts its function depending on cell type. FSTL1 differentially regulates TGF- $\beta$ and BMP signaling, leading to epithelial injury and fibroblast activation. The precise mechanisms by which FSTL1 exerts its function, if and how FSTL1 regulates epithelial apoptosis, fibroblast proliferation/migration, and myofibroblasts' prolonged survival, are actively pursued in our laboratories. This study and our continuing efforts will provide novel insights into the understanding of the molecular mechanisms of IPF and a novel therapeutic target for patients with pulmonary fibrosis.

\section{MATERIALS AND METHODS}

Subjects. Lung tissue samples from IPF patients $(n=5)$ obtained from bronchoscopy lung biopsies, used for qRT-PCR analysis of FSTL1 expression, were from the Capital Medical University Tissue Bank (Beijing, China). The IPF patients were diagnosed by physical examination, pulmonary function studies, chest high-resolution computed tomography, and BAL findings according to the respective diagnostic criteria for this disease (ATS/ERS, 2000). They were two females and three males, with a mean age of $63.2 \mathrm{yr}$ old, ranging from 53 to $67 \mathrm{yr}$. The mean FEV1 was $58.9 \pm 13.8 \%$. Age- and sex-matched control samples, including normal histology lung samples from patients with lung cancer $(n=4)$ or from transplant donor $(n=1$; Table S1) were used. This study was approved by the Institutional Review Board for Human Subject Research at Capital Medical University. Human primary pulmonary fibroblasts (Wang et al., 2006) were provided by C.A. FeghaliBostwick (University of Pittsburgh School of Medicine, Pittsburgh, PA). We cultured cells in DMEM (Gibco) supplemented with 10\% FBS (Hyclone) and antibiotics in $5 \% \mathrm{CO}_{2}$ at $37^{\circ} \mathrm{C}$ in a humidified atmosphere. Cells were grown to $100 \%$ confluence and extracted for qRT-PCR analysis. The cells were used from three to five generations.

Mice, bleomycin administration, and BAL. Fst $t 1^{f 0 x /+}$ mice were provided by X. Gao (Nanjing University, Nanjing, China). Fst $t 1^{+/-}$mice were generated as previously described (Geng et al., 2011). The mice have been crossed onto the C57BL/6J background for at least 12 generations before use. C57BL/6J mice at $8 \mathrm{wk}$ were purchased from Model Animal Research Center of Nanjing University. All mice were housed and cared for in a pathogen-free facility at Nankai University. All animal experiments were approved by the Animal Care and Use Committee at Nankai University. Intratracheal bleomycin administration, collection of BALF, and cytospin preparation for BALF cells were performed as described previously (Jiang et al., 2004). In brief, mice were anaesthetized with chloral hydrate (Sangon) and then intratracheally injected with bleomycin (Blenoxane, Nippon Kayaku Co Ltd) at either a dose of $5 \mathrm{U} / \mathrm{kg}$ body weight for analysis of the survival or $2.5 \mathrm{U} / \mathrm{kg}$ body weight for analysis of the fibrotic response. At designated time points after bleomycin injection, mice were euthanized with chloral hydrate by i.p. injection, hearts were perfused with PBS through the right ventricle until lungs cleared of blood, and lungs were harvested for further analyses. For BAL, the trachea was cannulated and lavaged three times with $0.8 \mathrm{ml}$ sterile PBS at room temperature. Samples were centrifuged at 1,500 rpm for $5 \mathrm{~min}$, and the cell-free supernatants were collected for ELISA assay. The cell pellets were recovered in $1 \mathrm{ml}$ sterile PBS, and the cells were counted with a hemocytometer. Cytospin preparations of BALF cells were stained with hematoxylin and eosin and viewed under light microscopy for inflammatory cell differential.

Hydroxyproline assay. Collagen contents in right lungs cleared of blood were measured with a conventional hydroxyproline method (Jiang et al., 2004). The ability of the assay to completely hydrolyze and recover hydroxyproline from collagen was confirmed using samples containing known amounts of purified collagen.

Histology and immunohistochemistry. The trachea was cannulated, and the left lungs cleared of blood were inflated with $0.5 \mathrm{ml}$ of $10 \%$ neutral 
buffered formalin. The tissues were then fixed overnight, embedded in paraffin, and sectioned for staining with hematoxylin and eosin or Masson's trichrome to assess the degree of fibrosis. Quantification of pulmonary fibrosis was performed as described previously (Jiang et al., 2004). In brief, slides stained with trichrome were examined under high power and scored for a total of 10 random fields per specimen. Digitized images were analyzed by Image Pro-Plus 6.0 software (Media Cybernetics). The overall and fibrotic areas of the lung were outlined, the pixels of total versus fibrotic tissue were summed over each lung, and a percentage was obtained.

Immunohistochemistry was performed as previously described (Geng et al., 2011). In brief, 5- $\mu \mathrm{m}$ sections were deparaffinized and rehydrated.After the antigen was recovered by high-pressure heating with citrate buffer (Maxin Bio), tissues were incubated with different antibody at $4^{\circ} \mathrm{C}$ overnight and HRP-polymer secondary antibodies (Maxin Bio) for 15 min and then incubated and developed using DAB solution (Maxin Bio). The antibody specific for FSTL1 (Abmart), Endomucin (eBioscience), type I collagen, pro-SPC (Abcam), $\alpha$-SMA (Santa Cruz Biotechnology, Inc.), or vimentin (NeoMarkers) was used for staining. Alexa Fluor 488- and Alexa Fluor 633-conjugated secondary antibodies are both from Invitrogen. The nucleus was labeled with DAPI (Santa Cruz Biotechnology, Inc.), photographed with a TCS SP5 confocal microscope (Leica), and analyzed by confocal software (Leica).

Cell line culture. Human pulmonary epithelial cell line A549, human hepatoma cell line Hep3B, human embryonic kidney cell line HEK293, and monkey kidney fibroblast cell line COS-7 were obtained from ATCC. We cultured all cells in DMEM supplemented with 10\% FBS and antibiotics in $5 \% \mathrm{CO}_{2}$ at $37^{\circ} \mathrm{C}$ in a humidified atmosphere.

AEC isolation and culture. Primary AECs were isolated from saline- and bleomycin-treated mice as previously described (Jiang et al., 2005). In brief, lungs were lavaged three times with $1 \mathrm{ml}$ PBS and digested with dispase II and minced. The digested lung pieces were filtered through $100-$ and $40-\mu \mathrm{m}$ cell strainers and centrifuged. The cell pellet was resuspended in DMEM containing $10 \% \mathrm{FBS}$, and negative selection for lymphocytes/macrophages was performed by incubation on CD16/32- and CD45-coated dishes for $45 \mathrm{~min}$ at $37^{\circ} \mathrm{C}$. Negative selection for fibroblasts was performed by adherence for $45 \mathrm{~min}$ on dishes. Cells were cultured on Collagen I-coated plates (BD) for a maximum of $3 \mathrm{~d}$ in $5 \% \mathrm{CO}_{2}$ at $37^{\circ} \mathrm{C}$ in a humidified atmosphere. Newly isolated AECs were used for FACS analysis. AECs cultured for $3 \mathrm{~d}$ were used for examination of TGF- $\beta / \mathrm{BMP}$ signaling and Fstl1 mRNA.

Fibroblast isolation and culture. Primary fibroblasts isolated from salineand bleomycin-treated mice were cultured in DMEM supplemented with $10 \% \mathrm{FBS}$ and antibiotics in $5 \% \mathrm{CO}_{2}$ at $37^{\circ} \mathrm{C}$ in a humidified atmosphere as described previously (Ning et al., 2004). Newly isolated lung fibroblasts were used for FACS analysis. Newly isolated lung fibroblasts cultured in DMEM with $10 \%$ FBS for $24 \mathrm{~h}$ on the cover slice were used for immunostaining analysis. For TGF- $\beta 1$ treatment, cells were treated with $5 \mathrm{ng} / \mathrm{ml}$ TGF- $\beta 1$ (R\&D Systems) $24 \mathrm{~h}$ after serum starvation. Cells of passage 1 were used for examination of TGF- $\beta$ /BMP signaling and Fstl1 mRNA. Cells of passages 3-4 were used for myofibroblast activation and ECM production assays. After the indicated length of time of $5 \mathrm{ng} / \mathrm{ml}$ TGF- $\beta 1$ treatment with/without $100 \mathrm{ng} / \mathrm{ml} \mathrm{FSTL1}$ protein (Li et al., 2013), fibroblasts and cultured medium were collected separately, and the $\alpha$-SMA expression in cell extracts or the ECM production in supernatants of medium was measured using Western blot analysis.

AEC-fibroblast co-culture system. Newly isolated primary AECs were cultured in the Collagen I-coated upper chamber of a transwell (pore size $0.4 \mu \mathrm{m}$; Costar Corp), whereas newly isolated fibroblasts were cultured in the lower plate, respectively. After 2-d culture, the upper chamber was inserted back into the lower plate, and AECs were co-cultured with fibroblasts in a serum-free medium for another $24 \mathrm{~h}$. Newly isolated AECs were also co-cultured directly with fibroblasts at a ratio of 1:10 in a serum-free DMEM/F12 (1:1) medium for $48 \mathrm{~h}$. Fibroblasts were collected and used for further myofibroblast activation and ECM production assays.
Western blot analysis and pull-down assay. The proteins were extracted from cells or tissue following standard protocols as described previously (Ning et al., 2004). All lung tissues used in Western blot analysis were cleared of blood by heart perfusion with PBS through the right ventricle, except those for the assay of FSTL1 expression after bleomycin treatment. Nuclear and cytoplasmic proteins were isolated using a Nuclear Protein Extraction kit (Beyotime Biotechnology). For Western blotting analysis, the antibodies were used to recognize the proteins: FSTL1, Fibronectin, Collagen I, $\alpha$-SMA, $\beta$-actin, His, HA, and Myc (Santa Cruz Biotechnology, Inc.); p-Smad2, Smad2, p-Smad3, Smad3, p-Smad2,3, p-Smad1, Smad1, and $\alpha$-tubulin (Cell Signaling Technology); N-cadherin, E-cadherin, and pro-SPC (Abcam); and TGF- $\beta 1$ (R\&D Systems). For pull-down assay, Histagged FSTL1 was concentrated by Ni-NTA-agarose beads (QIAGEN), which could capture His-tagged proteins. After washing, the beads were incubated with TGF- $\beta 1$ solution. The Ni-FSTL1-bounded TGF- $\beta 1$ was then analyzed by immunoblotting with anti-TGF- $\beta 1$ antibodies. The unspecific IgG antibodies were used as a control. HEK293 cells were transfected with Myc-His-tagged Fstl1 and HA-tagged type II receptor of TGF$\beta 1$ (T $\beta R I I)$ or type I receptor of TGF- $\beta 1$ (T $\beta R I)$ with Lipofectamine (Invitrogen). In vitro-translated Myc-His-tagged FSTL1 was concentrated by Ni-NTA-agarose beads, and the Ni-FSTL1-bounded HA receptors were then analyzed by immunoblotting with anti-HA antibodies. COS-7 cells were transfected with HA-tagged T $\beta$ RII with Lipofectamine (Invitrogen). In vitro-translated HA-tagged T $\beta R$ II was immunoprecipitated by HA-agarose and incubated with TGF- $\beta 1$ and FSTL1 proteins to examine how FSTL1 facilitates the binding of TGF- $\beta 1$ to T $\beta$ RII.

Expression profile dataset and analysis. Gene profiling dataset of IPF lungs analyzed for FSTL1 expression was acquired from a previous study (Pardo et al., 2005). The complete set of gene array data is in the National Center of Biotechnology Information Gene Expression Omnibus under accession no. GSE2052.

qRT-PCR analysis. We performed RNA isolation and qRT-PCR analysis as previously described (Geng et al., 2011). The expression of FSTL1, Fstl1, Fsp1, $\boldsymbol{\alpha}$-SMA, Col1a1, fibronectin (Fn1), TGF- $\boldsymbol{\beta} 1$, Sftpc, SFTPC, E-cadherin (Cdh1), Occludin (Ocln), ZO- $1^{+}, \mathrm{ZO}-1^{-}$, and vimentin (Vim) was determined using the SYBR Green Master Mix kit (Roche). Human $\beta$-glucuronidase (GUSB) or mouse $\boldsymbol{\beta}$-actin was used as an internal control. Gene expressions were measured relative to the calibrator RNA sample, human lung tissue or lung fibroblast RNA, mouse lung tissue or lung fibroblast RNA, or mouse lung AECs RNA, which were amplified parallelly. The sequences of specific primer pairs are described below: FSTL1 (NM_007085.4), 5'-TCTGTGCCAATGTGTTTTGTGG-3' and 5' -TGAGGTAGGTCTTGCCATTACTG-3'; Fstl1 (NM_008047.5), 5' -TTATGATGGGCACTGCAAAGAA-3' and 5'-ACTGCCTTTAGAGAACCAGCC-3'; $\boldsymbol{\beta}$-actin (NM_007393.3), 5'-AGGCCAACCGTGAAAAGATG-3' and 5'-AGAGCATAGCCCTCGTAGATGG-3'; GUSB (NM_000181.3), 5' -CCAAACCAGCCTGACAACTT-3' and 5'-TCTAGCATGCTCCACCACTG-3'; Fn1 (NM_010233.1), 5'-GTGTAGCACAACTTCCAATTACGAA-3' and 5'-GGAATTTCCGCCTCGAGTCT-3'; Col1a1 (NM_007742.3), 5'-CCAAGAAGACATCCCTGAAGTCA- $3^{\prime}$ and $5^{\prime}$-TGCACGTCATCGCACACA-3'; $\boldsymbol{\alpha}$-SMA (NM_007392.2), 5'-GCTGGTGATGATGCTCCCA- $3^{\prime}$ and $5^{\prime}$-GCCCATTCCAACCATTACTCC-3'; TGF- $\boldsymbol{\beta} 1$ (NM_011577.1), 5' ${ }^{\prime}$-TTGCTTCAGCTCCACAGAGA- $3^{\prime}$ and $5^{\prime}$-GTTGGACAACTGCTCCACCT-3'; BMP4 (NM_007554.2), 5'-CCAAACGTAGTCCCAAGCAT- $3^{\prime}$ and $5^{\prime}$-TCAGTTCAGTGGGGACACAA- $3^{\prime}$; Cdh1 (NM_009864.2), 5'-CAGCCTTCTTTTCGGAAGACT-3' and 5'-GGTAGACAGCTCCCTATGACTG-3'; SFTPC (NM_001172410.1), 5'-CACCTGAAACGCCTTCTTATCG-3' and 5'-TGGCTCATGTGGAGACCCAT-3'; Sftpc (NM_011359.2), 5'-GAAGATGGCTCCAGAGAGCATC- $3^{\prime}$ and $5^{\prime}$-GGACTCGGAACCAGTATCATGC-3'; Ocln (NM_008756.2), 5'-TGATGCAGGTCTGCAGGAGTA-3' and 5'-TCTGCAGATCCCTTAACTTGC-3'; ZO-1+ (NM_009386.2), 5'-TCTCAACAGAAAGCAGAAGCC-3' and 5'-TCCTAAACAACCAGGCTGTGA-3'; 
ZO-1 ${ }^{-}$(NM_001163574.1), 5'-TCTCAACAGGTGTACAGGAAG-3' and 5'-TCAAGGTCTCTGCTGGCTTGT-3'; Fsp1 (NM_011311.2), 5'-AGGAGCTACTGACCAGGGAGCT- $3^{\prime}$ and $5^{\prime}$-TCATTGTCCCTGTTGCTGTCC-3'; Vim (NM_011701.4), 5'-CAGGATTTCTCTGCCTCTTCCA- $3^{\prime}$ and $5^{\prime}$-CCTGTCCGTCTCTGGTTTCAA- $3^{\prime}$.

Luciferase assay. Hep3B or A549 cells were cotransfected with luciferase reporters and the indicated plasmids, as well as $20 \mathrm{ng}$ Renilla-luciferase as an internal control, by using Lipofectamine (Invitrogen). $1 \mathrm{~d}$ after transfection, cells were treated with $20 \mathrm{ng} / \mathrm{ml} \mathrm{BMP} 4$ or $5 \mathrm{ng} / \mathrm{ml} \mathrm{TGF}-\beta 1$ with/without $100 \mathrm{ng} / \mathrm{ml} \mathrm{FSTL1}$ in DMEM containing $0.1 \%$ FBS. After washing with PBS, cells were harvested and the luciferase activity of cell lysates was determined using a luciferase assay system (Promega) as described by the manufacturer. Total light emission during the initial $20 \mathrm{~s}$ of the reaction was measured in a luminometer (Lumat LB 9501; Berthold). All assays were repeated in triplicate.

ELISA. Levels of TGF- $\beta 1$, IFN- $\gamma$, IL-13, IL-6, IL-1 $\beta$, IL-17A, and TNF (eBioscience) and BMP4 (CUSABIO) proteins in BALF and whole lung tissue lysates were measured with commercial ELISA kits according to the manufacturers' instructions. Lungs were harvested after perfusion to remove blood and were homogenized in $62.5 \mathrm{mM}$ Tris buffer with protease inhibitors before ELISA measurement.

FACS analysis. FACS analysis was performed as described previously (Jiang et al., 2004). Mouse lungs were harvested after perfusion to remove blood, and total cells in lungs were isolated using digestion buffer $(150 \mathrm{U} / \mathrm{ml}$ collagenase IV, $50 \mathrm{U} / \mathrm{ml}$ DNase I, and $5 \%$ FCS in PBS) at $37^{\circ} \mathrm{C}$ for $30 \mathrm{~min}$ and minced against a filter. The total population of cells, newly isolated AECs, and lung fibroblasts were analyzed by flow cytometry after staining with antibodies to CD3, CD4, CD8, NK1.1 (CD161), B220, CD11b, CD11c, Gr-1, IA-b, and E-cadherin (all from BD) and $\alpha$-SMA and Fsp1 (both from Abcam). FACS was performed on a FACSCalibur analytical flow cytometer (BD) and analyzed using FlowJo software.

FSTL1-neutralizing antibody. We raised $\mathrm{mAbs}$ against two mixed recombinant fractions of mouse FSTL1 protein in mice with conventional hybridoma techniques (commissioned through Abmart). Sequence of the recombinant fractions of mouse FSTL1 protein was as follows: 19-306 amino acids or 37-306 amino acids of full-length mouse FSTL1 protein (NP_ 009016.1). The recombinant fractions were produced by bacterial expression system. We screened several FSTL1 antibodies (clone 1F12 and 22B6) and identified one clone (22B6) that effectively blocked TGF- $\beta 1$-induced RNA expression of Col1a1 and fibronectin (Fn1) in lung fibroblasts.

Binding affinity of 22B6 to FSTL1 protein was assayed by SPR on a T200 instrument (Biacore) as described previously (Geng et al., 2011). In short, purified antibody (22B6) was immobilized on the sensor chip surface (CM5 sensor chip; Biacore). FSTL1 and Follistatin (ACRO Biosystems) ligand proteins in HBS-EP running buffer (Biacore) ran over 22B6 sensor-chip at $25^{\circ} \mathrm{C}$ at a flow rate of $10 \mu \mathrm{l} / \mathrm{min}$. After ligand flow ended, dissociation was monitored by a decrease in the resonance units. Binding affinity is expressed by $K_{\mathrm{d}}$; higher $K_{\mathrm{d}}$ means lower affinity of binding. Immunoprecipitation experiments were further used for analysis of specificity binding of 22B6 to FSTL1. FSTL1-, TGF- $\beta 1-$, or Follistatin (200 ng)-22B6 (2 $\mu \mathrm{g})$ complex was immunoprecipitated by protein $G$ agarose and subjected to Western blot analysis. Purified proteins were used as the positive control.

Neutralizing activity of 22B6 to FSTL1 was performed as follows. COS-7 cells transiently transfected with pc-Fstl1 plasmid were treated with $1 \mu \mathrm{g} / \mathrm{ml} 22 \mathrm{~B} 6$ or control IgG1. After $48 \mathrm{~h}$, supernatants were collected and used for ELISA analysis of IL-6. Serum-starved A549 cells (confluent) were pretreated with $1 \mu \mathrm{g} / \mathrm{ml} 22 \mathrm{~B} 6$ or control IgG1 for $1 \mathrm{~h}$ and then treated with $20 \mathrm{ng} / \mathrm{ml} \mathrm{BMP} 4$ with/without $100 \mathrm{ng} / \mathrm{ml} \mathrm{FSTL1}$ for another $24 \mathrm{~h}$. Total RNA was isolated with TRIzol (Invitrogen), and mRNA expression of SFTPC was measured by qRT-PCR. Primary neonatal rat ventricular myocytes (NRVMs) were prepared as described previously (Shimano et al., 2011).
NRVMs were incubated in DMEM supplemented with 10\% FBS for $48 \mathrm{~h}$ and serum starved for $24 \mathrm{~h}$. After pretreatment with $1 \mu \mathrm{g} / \mathrm{ml} 22 \mathrm{~B} 6$ or control IgG1 for $1 \mathrm{~h}$, NRVMs were treated with $100 \mathrm{ng} / \mathrm{ml} \mathrm{PE} \mathrm{(Sigma-Aldrich)}$ with/without $100 \mathrm{ng} / \mathrm{ml} \mathrm{FSTL1} \mathrm{for} \mathrm{another} 24 \mathrm{~h}$. Morphological changes were observed with a phage contrast light microscopy (DFC420C; Leica), and cell surface areas were examined by Image-Pro Plus version 6.0.

FSTL1-neutralizing antibody treatment in vitro. Primary mouse lung fibroblasts or primary fibroblasts from IPF lungs were grown to $100 \%$ confluence and serum starved for $24 \mathrm{~h}$. Cells were pretreated with $1 \mu \mathrm{g} / \mathrm{ml}$ antibody (22B6) or control IgG1 for $1 \mathrm{~h}$ and then treated with $5 \mathrm{ng} / \mathrm{ml}$ TGF- $\beta 1$. Fibroblasts and cultured medium were collected separately, and the Smad2/3 phosphorylation in cell extracts $30 \mathrm{~min}$ after TGF- $\beta 1$ treatment and $\alpha$-SMA expression in cell extracts or the ECM production in supernatants of medium $24 \mathrm{~h}$ after TGF- $\beta 1$ treatment were measured using Western blot analysis. Newly isolated AECs from C57BL/6J mice were cultured in the upper chamber of a Transwell for $2 \mathrm{~d}$. After $24 \mathrm{~h}$ of serum starving and $1 \mathrm{~h}$ of pretreatment with $1 \mu \mathrm{g} / \mathrm{ml}$ antibodies as indicated or control IgG1, AECs were treated with TGF- $\beta 1$ or BMP4, respectively, with/without FSTL1 for another $24 \mathrm{~h}$. The upper chamber was then inserted back into the lower plate with newly isolated fibroblasts cultured in it, and AECs were co-cultured with fibroblasts for another $24 \mathrm{~h}$. Co-cultured fibroblasts were collected, and mRNA expression of $\boldsymbol{\alpha}-S M A$, Col1a1, and fibronectin (Fn1) was measured using qRT-PCR analysis.

FSTL1-neutralizing antibody treatment in vivo. C57BL/6J mice were intratracheally administrated with $2 \mathrm{U} / \mathrm{kg}$ bleomycin. To investigate the role of neutralizing antibody during the early stage of fibrogenesis, FSTL1neutralizing antibody (clone 22B6) or its control isotype antibody (IgG1) was intraperitoneally injected ( $50 \mu \mathrm{g} /$ mouse/each time) on days $5,8,11$, respectively, after bleomycin treatment. The mouse lungs were harvested $14 \mathrm{~d}$ after bleomycin injury. During the late stage of fibrogenesis, FSTL1-neutralizing antibody (clone 22B6) or its control isotype antibody (IgG1) was intraperitoneally injected ( $50 \mu \mathrm{g} / \mathrm{mouse} / \mathrm{each}$ time) on days $8,11,14$, and 17 , respectively, after bleomycin treatment. The mouse lungs were harvested $21 \mathrm{~d}$ after bleomycin injury. Tissues were sectioned for Masson's trichrome to assess the degree of fibrosis. Collagen contents in the lung were measured with a conventional hydroxyproline method (Jiang et al., 2004).

Statistical analysis. Data are expressed as the mean \pm SEM. Differences in measured variables between experimental and control group were assessed by using Student's $t$ tests or Wilcoxon rank-sum test with nonparametric data. The survival curves were compared using the log-rank test. Results were considered statistically significant at $\mathrm{P}<0.05$. SPSS software was used for statistical analysis.

Online supplemental material. Fig. S1 shows specificity and neutralizing activity of FSTL1-neutralizing antibody. Table S1 shows clinical characteristics of the patients with IPF and donors. Online supplemental material is available at http://www.jem.org/cgi/content/full/jem.20121878/DC1.

We wish to thank X. Gao for providing Fst/1flox/+ mice, C.A. Feghali-Bostwick for providing primary lung fibroblasts isolated from IPF patients, J. Xu (Guangzhou Medical College, Guangzhou, China) for assisting with the bleomycin model setup, and Y.-G. Chen (Tsinghua University, Beijing, China) for assisting with SPR analysis.

This work was supported by Ministry of Science and Technology of China (973) grant 2009CB522101 (to W. Ning), National Natural Science Foundation of China (NSFC) grants 31071241, 31271559, and 81430001 (to W. Ning), National Institutes of Health (NIH) grant P01 HL108793 (to P.W. Noble and D. Jiang), and 111 project of China (B08011).

The authors declare no competing financial interests. 


\section{REFERENCES}

Agostini, C., and C. Gurrieri. 2006. Chemokine/cytokine cocktail in idiopathic pulmonary fibrosis. Proc. Am. Thorac. Soc. 3:357-363. http:// dx.doi.org/10.1513/pats.200601-010TK

Aoki, F., M. Kurabayashi, Y. Hasegawa, and I. Kojima. 2005. Attenuation of bleomycin-induced pulmonary fibrosis by follistatin. Am. J. Respir. Crit. Care Med. 172:713-720. http://dx.doi.org/10.1164/rccm.200412$1620 \mathrm{OC}$

ATS/ERS. 2000. American Thoracic Society. Idiopathic pulmonary fibrosis: diagnosis and treatment. International consensus statement. American Thoracic Society (ATS), and the European Respiratory Society (ERS) Am. J. Respir. Crit. Care Med. 161:646-664. http://dx.doi.org/10.1164/ ajrccm.161.2.ats3-00

Bonniaud, P., G. Martin, P.J. Margetts, K. Ask, J. Robertson, J. Gauldie, and M. Kolb. 2004. Connective tissue growth factor is crucial to inducing a profibrotic environment in "fibrosis-resistant" BALB/c mouse lungs. Am. J. Respir. Cell Mol. Biol. 31:510-516. http://dx.doi.org/10 $.1165 / \mathrm{rcmb} .2004-01580 \mathrm{OC}$

Borges, F.T., S.A. Melo, B.C. Özdemir, N. Kato, I. Revuelta, C.A. Miller, V.H. Gattone II, V.S. LeBleu, and R. Kalluri. 2013. TGF- $\beta 1$-containing exosomes from injured epithelial cells activate fibroblasts to initiate tissue regenerative responses and fibrosis. J. Am. Soc. Nephrol. 24:385-392. http://dx.doi.org/10.1681/ASN.2012101031

Bradshaw, A.D. 2012. Diverse biological functions of the SPARC family of proteins. Int. J. Biochem. Cell Biol. 44:480-488. http://dx.doi.org/10 $.1016 /$ j.biocel.2011.12.021

Chapman, H.A. 2011. Epithelial-mesenchymal interactions in pulmonary fibrosis. Annu. Rev. Physiol. 73:413-435. http://dx.doi.org/10.1146/ annurev-physiol-012110-142225

Clutter, S.D., D.C. Wilson, A.D. Marinov, and R. Hirsch. 2009. Follistatinlike protein 1 promotes arthritis by up-regulating IFN-gamma. J. Immunol. 182:234-239. http://dx.doi.org/10.4049/jimmunol.182.1.234

Costello, C.M., E. Cahill, F. Martin, S. Gaine, and P. McLoughlin. 2010. Role of gremlin in the lung: development and disease. Am. J. Respir. Cell Mol. Biol. 42:517-523. http://dx.doi.org/10.1165/rcmb .2009-0101TR

Dolan, V., M. Murphy, P. Alarcon, H.R. Brady, and C. Hensey. 2003. Gremlin - a putative pathogenic player in progressive renal disease. Expert Opin. Ther. Targets. 7:523-526. http://dx.doi.org/10.1517/14728222 .7.4.523

du Bois, R.M. 2010. Strategies for treating idiopathic pulmonary fibrosis. Nat. Rev. Drug Discov. 9:129-140. http://dx.doi.org/10.1038/nrd2958

Farkas, L., D. Farkas, J. Gauldie, D. Warburton, W. Shi, and M. Kolb. 2011. Transient overexpression of Gremlin results in epithelial activation and reversible fibrosis in rat lungs. Am. J. Respir. Cell Mol. Biol. 44:870-878. http://dx.doi.org/10.1165/rcmb.2010-0070OC

Gauldie, J., P. Bonniaud, P. Sime, K. Ask, and M. Kolb. 2007. TGF- $\beta$, Smad3 and the process of progressive fibrosis. Biochem. Soc. Trans. 35:661664. http://dx.doi.org/10.1042/BST0350661

Geng, Y., Y. Dong, M. Yu, L. Zhang, X. Yan, J. Sun, L. Qiao, H. Geng, M. Nakajima, T. Furuichi, et al. 2011. Follistatin-like 1 (Fstl1) is a bone morphogenetic protein (BMP) 4 signaling antagonist in controlling mouse lung development. Proc. Natl. Acad. Sci. USA. 108:7058-7063. http://dx.doi.org/10.1073/pnas.1007293108

Goodwin, A., and G. Jenkins. 2009. Role of integrin-mediated TGF $\beta$ activation in the pathogenesis of pulmonary fibrosis. Biochem. Soc. Trans. 37:849-854. http://dx.doi.org/10.1042/BST0370849

Grütter, C., T. Wilkinson, R. Turner, S. Podichetty, D. Finch, M. McCourt, S. Loning, L. Jermutus, and M.G. Grütter. 2008. A cytokineneutralizing antibody as a structural mimetic of 2 receptor interactions. Proc. Natl. Acad. Sci. USA. 105:20251-20256. http://dx.doi.org/10.1073/ pnas.0807200106

Hagimoto, N., K. Kuwano, I. Inoshima, M. Yoshimi, N. Nakamura, M. Fujita, T. Maeyama, and N. Hara. 2002. TGF- $\beta 1$ as an enhancer of Fasmediated apoptosis of lung epithelial cells. J. Immunol. 168:6470-6478. http://dx.doi.org/10.4049/jimmunol.168.12.6470

Horan, G.S., S. Wood, V. Ona, D.J. Li, M.E. Lukashev, P.H. Weinreb, K.J. Simon, K. Hahm, N.E. Allaire, N.J. Rinaldi, et al. 2008. Partial inhibition of integrin $\alpha v \beta 6$ prevents pulmonary fibrosis without exacerbating inflammation. Am. J. Respir. Crit. Care Med. 177:56-65. http://dx.doi .org/10.1164/rccm.200706-805OC

Jiang, D., J. Liang, J. Hodge, B. Lu, Z. Zhu, S. Yu, J. Fan, Y. Gao, Z. Yin, R. Homer, et al. 2004. Regulation of pulmonary fibrosis by chemokine receptor CXCR3. J. Clin. Invest. 114:291-299. http://dx.doi .org/10.1172/JCI16861

Jiang, D., J. Liang, J. Fan, S. Yu, S. Chen, Y. Luo, G.D. Prestwich, M.M. Mascarenhas, H.G. Garg, D.A. Quinn, et al. 2005. Regulation of lung injury and repair by Toll-like receptors and hyaluronan. Nat. Med. 11:1173-1179. http://dx.doi.org/10.1038/nm1315

Kage, H., and Z. Borok. 2012. EMT and interstitial lung disease: a mysterious relationship. Curr. Opin. Pulm. Med. 18:517-523.

Kim, K.K., M.C. Kugler, P.J. Wolters, L. Robillard, M.G. Galvez, A.N. Brumwell, D. Sheppard, and H.A. Chapman. 2006. Alveolar epithelial cell mesenchymal transition develops in vivo during pulmonary fibrosis and is regulated by the extracellular matrix. Proc. Natl. Acad. Sci. USA. 103:13180-13185. http://dx.doi.org/10.1073/pnas.0605669103

King, T.E. Jr., A. Pardo, and M. Selman. 2011. Idiopathic pulmonary fibrosis. Lancet. 378:1949-1961. http://dx.doi.org/10.1016/S0140-6736(11)60052-4

Koli, K., M. Myllärniemi, K. Vuorinen, K. Salmenkivi, M.J. Ryynänen, V.L. Kinnula, and J. Keski-Oja. 2006. Bone morphogenetic protein-4 inhibitor gremlin is overexpressed in idiopathic pulmonary fibrosis. $\mathrm{Am}$. J. Pathol. 169:61-71. http://dx.doi.org/10.2353/ajpath.2006.051263

Le Luduec, J.B., T. Condamine, C. Louvet, P. Thebault, J.M. Heslan, M. Heslan, E. Chiffoleau, and M.C. Cuturi. 2008. An immunomodulatory role for follistatin-like 1 in heart allograft transplantation. Am. J. Transplant. 8:2297-2306. http://dx.doi.org/10.1111/j.1600-6143.2008 .02398.x

Leask, A., and D.J. Abraham. 2004. TGF- $\beta$ signaling and the fibrotic response. FASEB J. 18:816-827. http://dx.doi.org/10.1096/fj.03-1273rev

Li, M., M.S. Krishnaveni, C. Li, B. Zhou, Y. Xing, A. Banfalvi, A. Li, V. Lombardi, O. Akbari, Z. Borok, and P. Minoo. 2011. Epitheliumspecific deletion of TGF- $\beta$ receptor type II protects mice from bleomycininduced pulmonary fibrosis. J. Clin. Invest. 121:277-287. http://dx.doi .org/10.1172/JCI42090

Li, L., X. Li, X. Liu, Y. Dong, Y. Geng, X. Liu, and W. Ning. 2013. Expression, characterization, and preliminary X-ray crystallographic analysis of recombinant murine Follistatin-like 1 expressed in Drosophila S2 cells. Biosci. Trends. 7:93-100.

Miyamae, T., A.D. Marinov, D. Sowders, D.C. Wilson, J. Devlin, R. Boudreau, P. Robbins, and R. Hirsch. 2006. Follistatin-like protein-1 is a novel proinflammatory molecule. J. Immunol. 177:4758-4762. http://dx .doi.org/10.4049/jimmunol.177.7.4758

Moeller, A., K. Ask, D. Warburton, J. Gauldie, and M. Kolb. 2008. The bleomycin animal model: a useful tool to investigate treatment options for idiopathic pulmonary fibrosis? Int. J. Biochem. Cell Biol. 40:362-382. http://dx.doi.org/10.1016/j.biocel.2007.08.011

Munger, J.S., X. Huang, H. Kawakatsu, M.J. Griffiths, S.L. Dalton, J. Wu, J.F. Pittet, N. Kaminski, C. Garat, M.A. Matthay, et al. 1999. The integrin $\alpha v \beta 6$ binds and activates latent TGF $\beta 1$ : a mechanism for regulating pulmonary inflammation and fibrosis. Cell. 96:319-328. http://dx.doi .org/10.1016/S0092-8674(00)80545-0

Myllärniemi, M., P. Lindholm, M.J. Ryynänen, C.R. Kliment, K. Salmenkivi, J. Keski-Oja, V.L. Kinnula, T.D. Oury, and K. Koli. 2008. Gremlin-mediated decrease in bone morphogenetic protein signaling promotes pulmonary fibrosis. Am. J. Respir. Crit. Care Med. 177:321329. http://dx.doi.org/10.1164/rccm.200706-945OC

Ning, W., C.J. Li, N. Kaminski, C.A. Feghali-Bostwick, S.M. Alber, Y.P. Di, S.L. Otterbein, R. Song, S. Hayashi, Z. Zhou, et al. 2004. Comprehensive gene expression profiles reveal pathways related to the pathogenesis of chronic obstructive pulmonary disease. Proc. Natl. Acad. Sci. USA. 101: 14895-14900. http://dx.doi.org/10.1073/pnas.0401168101

Noble, P.W., and R.J. Homer. 2004. Idiopathic pulmonary fibrosis: new insights into pathogenesis. Clin. Chest Med. 25:749-758: vii. http://dx .doi.org/10.1016/j.ccm.2004.04.003

Olson, A.L., J.J. Swigris, D.C. Lezotte, J.M. Norris, C.G. Wilson, and K.K. Brown. 2007. Mortality from pulmonary fibrosis increased in the United States from 1992 to 2003. Am. J. Respir. Crit. Care Med. 176:277-284. http://dx.doi.org/10.1164/rccm.200701-044OC 
Pardo, A., K. Gibson, J. Cisneros, T.J. Richards, Y. Yang, C. Becerril, S. Yousem, I. Herrera, V. Ruiz, M. Selman, and N. Kaminski. 2005. Up-regulation and profibrotic role of osteopontin in human idiopathic pulmonary fibrosis. PLoSMed.2:e251.http://dx.doi.org/10.1371/journal .pmed.0020251

Patella, S., D.J. Phillips, J. Tchongue, D.M. de Kretser, and W. Sievert. 2006. Follistatin attenuates early liver fibrosis: effects on hepatic stellate cell activation and hepatocyte apoptosis. Am. J. Physiol. Gastrointest. Liver Physiol. 290:G137-G144. http://dx.doi.org/10.1152/ajpgi.00080 .2005

Phan, S.H. 2012. Genesis of the myofibroblast in lung injury and fibrosis. Proc. Am. Thorac. Soc. 9:148-152. http://dx.doi.org/10.1513/pats .201201-011AW

Rock, J.R., C.E. Barkauskas, M.J. Cronce, Y. Xue, J.R. Harris, J. Liang, P.W. Noble, and B.L. Hogan. 2011. Multiple stromal populations contribute to pulmonary fibrosis without evidence for epithelial to mesenchymal transition. Proc. Natl. Acad. Sci. USA. 108:E1475-E1483. http:// dx.doi.org/10.1073/pnas.1117988108

Saito, F., S. Tasaka, K. Inoue, K. Miyamoto, Y. Nakano, Y. Ogawa, W Yamada, Y. Shiraishi, N. Hasegawa, S. Fujishima, et al. 2008. Role of interleukin-6 in bleomycin-induced lung inflammatory changes in mice. Am. J. Respir. Cell Mol. Biol. 38:566-571. http://dx.doi.org/10.1165/ rcmb.2007-0299OC

Scotton, C.J., and R.C. Chambers. 2007. Molecular targets in pulmonary fibrosis: the myofibroblast in focus. Chest. 132:1311-1321. http://dx.doi .org/10.1378/chest.06-2568

Selman, M., and A. Pardo. 2002. Idiopathic pulmonary fibrosis: an epithelial/fibroblastic cross-talk disorder. Respir. Res. 3:3. http://dx.doi.org/ $10.1186 / \mathrm{rr} 175$

Selman, M., A. Pardo, and N. Kaminski. 2008. Idiopathic pulmonary fibrosis: aberrant recapitulation of developmental programs? PLoS Med. 5:e62. http://dx.doi.org/10.1371/journal.pmed.0050062

Shannon, J.M., and B.A. Hyatt. 2004. Epithelial-mesenchymal interactions in the developing lung. Annu. Rev. Physiol. 66:625-645. http://dx.do .org/10.1146/annurev.physiol.66.032102.135749

Shibanuma, M., J. Mashimo, A. Mita, T. Kuroki, and K. Nose. 1993. Cloning from a mouse osteoblastic cell line of a set of transforming-growth-factor$\beta 1$-regulated genes, one of which seems to encode a follistatin-related polypeptide. Eur. J. Biochem. 217:13-19. http://dx.doi.org/10.1111/ j.1432-1033.1993.tb18212.x

Shimano, M., N. Ouchi, K. Nakamura, B. van Wijk, K. Ohashi, Y. Asaumi, A. Higuchi, D.R. Pimentel, F. Sam, T. Murohara, et al. 2011. Cardiac myocyte follistatin-like 1 functions to attenuate hypertrophy following pressure overload. Proc. Natl. Acad. Sci. USA. 108:E899-E906. http:// dx.doi.org/10.1073/pnas.1108559108
Sime, P.J., Z. Xing, F.L. Graham, K.G. Csaky, and J. Gauldie. 1997. Adenovector-mediated gene transfer of active transforming growth factor-beta 1 induces prolonged severe fibrosis in rat lung. J. Clin. Invest. 100:768-776. http://dx.doi.org/10.1172/JCI119590

Sountoulidis, A., A. Stavropoulos, S. Giaglis, E. Apostolou, R. Monteiro, S.M. Chuva de Sousa Lopes, H. Chen, B.R. Stripp, C. Mummery, E. Andreakos, and P. Sideras. 2012. Activation of the canonical bone morphogenetic protein (BMP) pathway during lung morphogenesis and adult lung tissue repair. PLoS ONE. 7:e41460. http://dx.doi.org/ 10.1371/journal.pone.0041460

Trombetta-eSilva, J., and A.D. Bradshaw. 2012. The function of SPARC as a mediator of fibrosis. Open Rheumatol. J. 6:146-155. http://dx.do .org/10.2174/1874312901206010146

Wang, X.M., Y. Zhang, H.P. Kim, Z. Zhou, C.A. Feghali-Bostwick, F. Liu, E. Ifedigbo, X. Xu, T.D. Oury, N. Kaminski, and A.M. Choi. 2006 Caveolin-1: a critical regulator of lung fibrosis in idiopathic pulmonary fibrosis. J. Exp. Med. 203:2895-2906. http://dx.doi.org/10.1084/ jem. 20061536

Willis, B.C., and Z. Borok. 2007. TGF- $\beta$-induced EMT: mechanisms and implications for fibrotic lung disease. Am. J. Physiol. Lung Cell. Mol. Physiol. 293:L525-L534. http://dx.doi.org/10.1152/ajplung.00163.2007

Wilson, M.S., and T.A. Wynn. 2009. Pulmonary fibrosis: pathogenesis, etiology and regulation. Mucosal Immunol. 2:103-121. http://dx.doi.org/ 10.1038/mi.2008.85

Wynn, T.A. 2008. Cellular and molecular mechanisms of fibrosis. J. Pathol. 214:199-210. http://dx.doi.org/10.1002/path.2277

Wynn, T.A. 2011. Integrating mechanisms of pulmonary fibrosis. J. Exp. Med. 208:1339-1350. http://dx.doi.org/10.1084/jem.20110551

Xu, J., X. Qi, J. Gong, M. Yu, F. Zhang, H. Sha, and X. Gao. 2012. Fstl1 antagonizes BMP signaling and regulates ureter development. PLoS ONE. 7:e32554. http://dx.doi.org/10.1371/journal.pone.0032554

Yang, J., S.E. Wheeler, M. Velikoff, K.R. Kleaveland, M.J. LaFemina, J.A. Frank, H.A. Chapman, P.J. Christensen, and K.K. Kim. 2013. Activated alveolar epithelial cells initiate fibrosis through secretion of mesenchymal proteins. Am. J. Pathol. 183:1559-1570. http://dx.doi. org/10.1016/j.ajpath.2013.07.016

Zhao, J., W. Shi, Y.L. Wang, H. Chen, P. Bringas Jr., M.B. Datto, J.P. Frederick, X.F. Wang, and D. Warburton. 2002. Smad3 deficiency attenuates bleomycin-induced pulmonary fibrosis in mice. Am. J. Physiol. Lung Cell. Mol. Physiol. 282:L585-L593.

Zwijsen, A., H. Blockx, W. Van Arnhem, J. Willems, L. Fransen, K. Devos, J. Raymackers, A. Van de Voorde, and H. Slegers. 1994. Characterization of a rat C6 glioma-secreted follistatin-related protein (FRP). Cloning and sequence of the human homologue. Eur. J. Biochem. 225:937-946. http://dx.doi.org/10.1111/j.1432-1033.1994.0937b.x 